\title{
SDU\%
}

\section{Multidimensional Welfare Comparisons of EU Member States Before, During, and After the Financial Crisis: A Dominance Approach}

by

M. Azhar Hussain, Nikolaj Siersbak and Lars Peter Østerdal

Discussion Papers on Business and Economics

No. 10/2017

FURTHER INFORMATION

Department of Business and Economics Faculty of Business and Social Sciences University of Southern Denmark Campusvej 55, DK-5230 Odense M 


\title{
Multidimensional Welfare Comparisons of EU Member States Before, During, and After the Financial Crisis: A Dominance Approach
}

\author{
M. Azhar Hussain ${ }^{\dagger}$, Nikolaj Siersbæk ${ }^{\ddagger *}$, Lars Peter $\emptyset_{\text {sterdal }}{ }^{\S}$ \\ $\dagger$ Department of Social Sciences and Business, Roskilde University. \\ $\ddagger$ Department of Business and Economics \& COHERE, University of Southern Denmark. \\ ${ }^{\S}$ Department of Economics, Copenhagen Business School.
}

\begin{abstract}
How did the financial crisis affect population welfare in EU member states in key dimensions such as income, health, and education? Using EU-SILC data, we seek to answer this question by way of first order dominance comparisons between countries and over time. The novel feature of our study is that we perform welfare comparisons on the basis of multi-level multidimensional ordinal data. We find that the countries most often dominated are southern and eastern European member states, and the dominant countries are mostly northern and western European member states. However, for most country comparisons, there is no dominance relationship. Moreover, only a few member states have experienced a temporal dominance improvement in welfare, and no member states have experienced a dominance deterioration.
\end{abstract}

JEL classifications: I3, I31, O52.

Keywords: First order dominance $\cdot$ Multidimensional well-being $\cdot$ Multi-level indicators $\cdot$ EUSILC]

\section{Introduction}

The recent financial and economic crisis has had a major impact on EU member states. The effects on key macroeconomic indicators at the country level such as

\footnotetext{
${ }^{*}$ Corresponding author: Nikolaj Siersbæk, Department of Business and Economics \& COHERE, University of Southern Denmark, Campusvej 55, DK-5230 Odense M, Denmark. E-mail: nisie@sam.sdu.dk.

We are grateful to Andreas Bjerre-Nielsen, Dorte Gyrd-Hansen, Casper Worm Hansen, Giovanni Mellace, Troels Martin Range, Peter Sudhölter, and participants in the DGPE 2015 workshop (Sønderborg) for useful inputs and comments.
} 
GDP growth, public debt, inflation, etc. have been widely analyzed (e.g., European Commission, 2009). It has been shown that the financial and economic crisis has affected income at the individual level (e.g., De Beer, 2012). However, it has long been recognized that welfare is a multidimensional phenomenon, which is thus not adequately characterized by a single income dimension (e.g., Sen, 1970, 1973, 1976, 1985; Arrow, 1971; Kolm, 1977). Two questions are discussed in this paper: How has the crisis changed the relative multidimensional welfare of EU member states? Has multidimensional welfare improved or deteriorated over time for each state?

Previous multidimensional welfare comparisons of European countries have used methods that rely on a priori assumptions about the relative importance of different dimensions of welfare and a weighting scheme reflecting these. Examples of such methods are the Human Development Index (HDI), which focuses on three dimensions of welfare, namely a long and healthy life, being knowledgeable, and having a decent standard of living (UNDP, 1990, 2014), and the Multidimensional Poverty Index (MPI; e.g., Alkire and Apablaza, 2016) The weights assigned to each dimension in these methods are convenient for applications. In particular, the procedure always enables the analyst to rank the compared populations since a single measure of welfare is obtained. The approach is justified when there is broad agreement about which weights to apply. In practice, all dimensions are often weighted equally (e.g., Alkire et al., 2015) since there is no natural or generally agreed methodology for how to determine these weights. As Ravallion (2011) points out, the producer of the index is essentially free to set the unusually large number of "moving parts" that make up the index. Even if there is wide agreement that one dimension should be given a higher weight than another, it is rarely clear how this should be translated into actual weights. In addition, it is likely that there are significant individual and country differences in EU member states' preferences for given dimensions of welfare. One specific weighting scheme may thus not be appropriate to describe generic preferences in all European countries.

The challenges described above have fostered a focus on methods that are robust to different weighting schemes in multidimensional welfare comparisons. These methods enable comparisons across different weighting schemes or, put differently, broad classes of underlying social welfare functions (e.g., Atkinson and Bourguignon, 1982, 1987; Bourguignon, 1989; Atkinson, 1992; Bourguignon and Chakravarty, 2003, Duclos et al., 2006, 2007; Gravel et al., 2009; Gravel and Mukhopadhyay, 2010: Duclos and Échevin, 2011; Muller and Trannoy, 2011). A common feature of the above-mentioned studies is the application of conditions that are typically formulated in terms of specified signs on the second (or higher) order partial or cross-derivatives of the underlying social welfare function. Specifically, either sub-

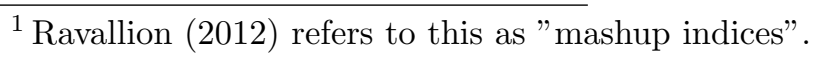


stitutability or complementarity between dimensions is assumed, for example that health and education are substitutes. These methods rely on specific classes of social welfare functions, and, while being largely robust to weighting, they do not apply to ordinal data.

In this paper we make multidimensional population welfare comparisons without relying on a priori chosen weights, nor on methods that assume a specific class of social welfare functions that require cardinal data. The natural concept for such comparisons is first order (stochastic) dominance (FOD), also known as the usual (multivariate) stochastic order in probability theory (e.g., Shaked and Shanthikumar, 2007). For finite distributions, one distribution first order dominates another if and only if the other distribution can be obtained from the first by iteratively shifting probability mass from better to worse outcomes. The FOD approach provides a way of making comparisons of multidimensional welfare that is robust to different weighting schemes. That is, it allows comparisons without making assumptions about utility functions and/or social welfare functions other than nondecreasingness. Thus, ordinal indicators can be used in the FOD procedure (Arndt et al., 2012); i.e., it is only required that outcomes can be ranked from worse to better within each dimension.

Previous applications of FOD have used only binary indicators to represent the included dimensions (see Arndt and Tarp, 2017 for a collection of studies applying FOD in developing countries using binary indicators). In this paper, we incorporate multi-level indicators; i.e., within each indicator, more than two levels are allowed. For example, we apply five levels of subjective health ranging from "very bad health" to "very good health". This mitigates one of the drawbacks of binary indicator-based FOD since a finer classification of indicators lowers the risk of drawing conclusions driven by an arbitrary choice of the threshold between levels for a given welfare indicator (see Section 6 for further discussion).

A linear programming approach has been the preferred method for identifying dominances (e.g., Arndt et al., 2012; Arndt and Tarp, 2017) following the theoretical foundation outlined in Mosler and Scarsini (1991) and Dyckerhoff and Mosler (1997). Here, we use an exact identification by use of a definition of FOD that has not previously been applied in the empirical literature. This relies on the identification of all lower comprehensive sets (LCSs) of outcomes and comparing population shares for each such set.

In our comparisons of EU member states, we include three multi-level indicators of the welfare dimensions income, health, and education, which have four, five, and three ordered levels, respectively, yielding a total of sixty different outcomes. We make spatial analyses of countries relative to each other within a given year as well as temporal analyses of countries over time. We find between 40 and 45 multidi- 
mensional dominances in each of the three years analyzed (2005, 2009, and 2013) out of 276 potential dominances each year, and only a few temporal dominances.

In the spatial analyses, the countries that are most often dominated are southern European countries (Italy, Portugal, and Spain) and eastern European countries (Hungary, Lithuania, Latvia, Poland, and Slovenia), whereas the dominant countries are most often northern and western European countries (Austria, Germany, Ireland, the Netherlands, Sweden, and the United Kingdom). In the temporal analyses, only a few countries have experienced a FOD improvement in welfare and no country has experienced a FOD deterioration in welfare over the period. Different patterns often appear from the separate one-dimensional analyses and the corresponding multidimensional analysis. These results highlight the importance of a multidimensional view in welfare analyses.

The paper is structured as follows. Section 2 briefly reviews related empirical literature on multidimensional welfare in Europe. Section 3 describes the concept of FOD in a multidimensional welfare setting, followed by a description of a method for identifying dominances empirically and the Copeland (1951) method for providing a ranking based on pairwise (dominance) comparisons. Section 4 describes the EUSILC data applied. The results are shown in Section 5 and discussed in Section 6 . Lastly, Section 7 summarizes and concludes.

\section{Related empirical literature}

The United Nations Development Program (UNDP) publishes the Human Development Index (HDI) for most of the world's sovereign countries and states as a measure of progress in a given country (UNDP, 2014). Their focus is on three dimensions of welfare, namely a long and healthy life, being knowledgeable, and having a decent standard of living. The indicators of each dimension are life expectancy at birth, mean years of schooling and expected years of schooling, and purchasing power parity (PPP) adjusted gross national income (GNI) per capita, respectively. Both the two intra-education indicators making up the education dimension and the three dimensions in the HDI are weighted equally by $\frac{1}{2}$ and $\frac{1}{3}$, respectively $\left.\right|^{2}$

The UNDP also publishes the Multidimensional Poverty Index (MPI, sometimes denoted $M_{0}$ ), but only for developing countries. Furthermore, the year of the surveys used to calculate the MPI in a given year differs significantly (e.g., UNDP, 2014, Table 6, pages 180-181). However, in a recent paper, Alkire and Apablaza (2016) (building on Alkire et al., 2014) explore multidimensional poverty in Europe using

\footnotetext{
${ }^{2}$ Note that there can be multiple indicators for the same welfare dimension as exemplified here, where both mean years of schooling and expected years of schooling are used as indicators in the education dimension. In this paper, we use one indicator for each welfare dimension included. "Dimension" and "indicator" may thus be used interchangeably throughout the paper.
} 
MPI on EU-SILC data in 2006, 2009, and 2012 following the Alkire-Foster methodology (Alkire and Foster, 2011a; Alkire and Foster, 2011b; Foster et al., 1984; and see also Alkire et al., 2015). The MPI applied in Alkire and Apablaza (2016) includes twelve binary indicators in six dimensions: income, employment, material deprivation, education, environment, and health $3^{3}$

Other studies of welfare in a European context are available in the literature. They generally apply dimensions and/or indicators that are very different from the ones used in the present paper (see Section 4 for a description). For example, Bossert et al. (2013) and Whelan et al. (2014) use a weighting scheme and a deprivation approach. Hussain (2016) shows the HDI, MPI, FOD, and more using EU-SILC data on deprivations, which is the only other empirical application of FOD on European countries.

Both UNDP (2014) and Alkire and Apablaza (2016) find that the highest ranked countries (with highest HDI or lowest MPI, respectively) are northern and western European countries, whereas the lowest ranked countries are southern and eastern European countries. Although the methods and data differ, we expect to find rather similar results in general. However, even though the HDI and/or MPI indicates that one country is better off than another, we may in contrast obtain an indeterminate result.

\section{Methodology 4}

Suppose that welfare is measured in $N$ dimensions and let $X \subseteq \mathbb{R}^{N}$ be a finite set of multidimensional outcomes. A distribution of welfare is described by a probability mass function $f$ over $X$ (i.e. $\sum f(x)=1$ and $f(x) \geq 0$ for all $x \in X$ ). We refer to $f$ as a distribution. A subset $Y \subseteq X$ is a lower comprehensive set (LCS) if $x \in Y$, $y \in X$, and $y \leq x$ implies $y \in Y$. A distribution $f$ first order dominates distribution $g$ if and only if

(i) $\sum_{x \in Y} g(x) \geq \sum_{x \in Y} f(x)$ for all $Y \subseteq X$.

It is well-known that definition (i) of FOD is equivalent to the following two definitions: (ii) $g$ can be obtained from $f$ by a finite number of shifts of probability mass from one outcome to another that is worse, and (iii) social welfare is weakly higher for $f$ than for $g$ for any nondecreasing additively separable social welfare function;

\footnotetext{
${ }^{3}$ For example, an indicator in the health dimension is that the respondent considers her own health as fair or above, and the indicator in the education dimension is whether or not the respondent has completed primary education.

${ }^{4}$ For a review of FOD in both a one-dimensional and multidimensional welfare setting using binary indicators, we refer to Siersbæk et al. (2017).
} 
i.e., $\sum_{x \in X} f(x) w(x) \geq \sum_{x \in X} g(x) w(x)$ for any weakly increasing real function $w(\cdot) !^{5}$

Note that FOD only requires ordinal data and that it is absent of assumptions about the strength of preferences for each dimension, the relative desirability of changes among levels within or between dimensions, and the complementarity/substitutability among the dimensions (Arndt et al., 2012). This makes FOD applicable to a wide range of indicators, whereas, e.g., dominance concepts as in Atkinson and Bourguignon (1982, 1987) require cardinal indicators.

Using definition (ii), Mosler and Scarsini (1991) and Dyckerhoff and Mosler (1997) show that identifying FOD corresponds to checking if a certain linear program has a feasible solution. The first empirical implementation of this approach was provided by Arndt et al. (2012) in a study of child poverty in Mozambique and Vietnam with multiple binary indicators (see also Arndt and Tarp, 2017). In this paper, we identify dominances using definition (i), which is an exact test of dominance. To the authors' knowledge, this approach has not previously been applied to identify multidimensional population welfare. ${ }^{6}$

When we test for FOD using definition (i), one challenge is that the number of LCSs increases drastically when more dimensions and/or levels are included in the analysis. The number of LCSs is quantified by Sampson and Whitaker (1988) using the number of levels in each indicator 77 Generally, one has to carefully consider the number of dimensions as well as the number of levels of each indicator, as there is a trade-off between adequate characterization of welfare and increasing computational complexity of checking dominances. We first identify all LCSs using an iterative algorithm available from the authors. After the identification of all LCSs, checking for FOD using definition (i) is straightforward. 8

When comparing two populations it may be the case that none of them dominates the other. Thus, generally we are unable to obtain a complete ranking of all

\footnotetext{
${ }^{5}$ The first proof of the equivalence between (i) and (iii) is usually attributed to Lehmann (1955) (however, see also Levhari et al., 1975). The first formulation and proof of the equivalence between (i) and (ii) is not easy to trace back to its roots, but Kamae et al. (1977) observed that the equivalence between (i) and (ii) is a corollary of Strassen's Theorem (Strassen, 1965). Østerdal (2010) provides a constructive direct proof of this for the finite case.

${ }^{6}$ While linear programming is computationally faster, the approach may be challenged by numerical instability (see, e.g., Higham, 2002, for a general treatment). This may lead to the conclusion that a dominance exists when in fact there is no dominance (but "close").

${ }^{7}$ Strictly speaking, Sampson and Whitaker (1988) provide the number of upper comprehensive sets, which is, however, equal to the number of LCSs. For three dimensions with binary indicators, the total number of LCSs is 20 . If the number of levels of each indicator is three, the total number of LCSs is 980, and if four levels of each indicator are used, the total number of LCSs increases to 232,848 .

${ }^{8}$ The Matlab code for identifying all LCS and checking FOD is available on the following webpage: https://sites.google.com/site/nikolajsiersbaek/code. The empty LCS and the full set of all outcomes are omitted in the code since the corresponding sums using definition (i) are 0 and 1 , respectively. Computationally efficient algorithms capable of handling several indicators and levels is grounds for further research. For the bivariate case, efficient algorithms are provided in Range and Østerdal (2016).
} 
populations by way of FOD comparisons. However, the Copeland (1951) method can be used as a measure of the tendency to outperform other populations as an overall relative indicator of population well-being (Arndt et al., 2016; Siersbæk et al., 2017), which can be applied to the spatial analyses to obtain a ranking of the compared populations. The Copeland method involves counting, for each population $n$, how many of the $n-1$ other populations it dominates and subtracting the number of times it is dominated by the other populations. The corresponding Copeland score is in the interval $[-(n-1) ; n-1]$, which is normalized to $[-1 ; 1]$.

\section{Data}

The data applied are from the EU Statistics on Income and Living Conditions (EUSILC) database. We focus on the years 2005, 2009, and 2013 (i.e., before, during, and after the financial and economic crisis). As of 2005, the EU-SILC data cover all of the 25 member states at the time. The EU member states Bulgaria, Croatia, and Romania are therefore not included due to entry into the EU in 2007, 2013, and 2007 respectively. Furthermore, Malta is omitted due to insufficient data. The sample sizes for the member states range from 5,429 to 47,311 respondents in a given year (a complete overview is shown in Table A1 in Appendix A). All the data are collected based on the same (translated) questions in all EU member states using representative samples. We include three key dimensions of welfare: income, health, and education. Income is used in most measures of welfare. Health and education are prevalent in many measures of multidimensional welfare (e.g., World Bank, 1990; Alkire, 2002; UNDP, 2014; Alkire and Apablaza, 2016), and they have both been affected by the financial and economic crisis (e.g., Stuckler et al., 2009; Kentikelenis et al., 2011; OECD, 2013). The inclusion of these three particular dimensions also enables us to make interesting comparisons between our findings and welfare indices such as the HDI (UNDP, 2014) and the MPI (Alkire and Apablaza, 2016). Both of these indices use a weighting scheme and include indicators of health, education, and some measure of standard of living, typically income. The dimensions and indicators used in the present paper are described below and briefly summarized in Table 1.

We use individual equivalized annual net income as an indicator in the income dimension and correct it using PPP to facilitate cross-country comparisons $9^{9}$ Using EU quartiles in 2005 as thresholds, a four-level indicator is constructed. All incomes

\footnotetext{
${ }^{9}$ Equivalized total net income uses the OECD-modified scale (first proposed by Hagenaars et al., 1996). This assigns a weight of 1 to the first adult in the household, a weight of 0.5 to each additional member of the household aged 14 and over, and a weight of 0.3 to household members aged less than 14. The household's total net income is divided by this equivalized number of persons to get equivalized total net income (per person in the household). See http://www.oecd. org/eco/growth/OECD-Note-EquivalenceScales.pdf for more information.
} 
Table 1: Description of welfare dimensions and indicators

\section{Dimension Indicator Level Construction}

\begin{tabular}{llll}
\hline Income & Equivalized & 1 & First quartile $^{a}$ \\
& annual net & 2 & Second quartile $^{1}$ \\
& income & 3 & Third quartile $^{1}$ \\
& 4 & Fourth quartile \\
\hline \multirow{2}{*}{ Health } & Self-reported & 1 & Very bad \\
& health & 2 & Bad \\
& 3 & Fair \\
& & 4 & Good \\
& & 5 & Very good \\
\hline \multirow{2}{*}{ Education } & Highest ISCED & 1 & Pre-primary, primary, and lower secondary \\
& level obtained & 2 & Upper secondary and post-secondary \\
& & 3 & First ${ }^{c}$ and second stage tertiary
\end{tabular}

${ }^{a}$ Quartiles are based on the EU distribution of PPP-adjusted real income in 2005.

${ }^{b}$ Net income after transformation using equivalence scale weights.

${ }^{c}$ Not leading to an advanced research qualification.

${ }^{d}$ Leading to an advanced research qualification.

in 2009 and 2013 are deflated using the consumer price index (CPI). The indicator in the health dimension is self-reported health ranging from 1 (Very bad) to 5 (Very good); i.e., a five-level indicator. It includes different aspects of subjective health including physical, social, and emotional function and biomedical signs and symptoms. In the education dimension, we use the highest ISCED level obtained in three levels from 1 to 3 , where 3 is best ${ }^{10}$

The three indicators imply $4 \cdot 5 \cdot 3=60$ different outcomes. To identify dominances using definition (i), it is required to check 116,424 inequalities (Sampson and Whitaker, 1988). An illustration of the data setup that enables identification of FOD using the code available from the authors is shown in Table B1 in Appendix B using sample data for Germany in 2005 for all outcomes.

\section{Results}

Tables 2, 3, and 4 show the one-dimensional and multidimensional analyses in 2005, 2009, and 2013 respectively. "I" indicates that the row country dominates the column country in the income dimension. Similarly " $H$ " indicates dominance in the

\footnotetext{
${ }^{10}$ The ISCED (International Standard Classification of Education) is developed by UNESCO (United Nations Educational, Scientific and Cultural Organization) to facilitate cross-country comparisons of education systems since these vary in terms of structure. We use the ISCED 1997, which ranges from 0 (pre-primary education) to 6 (second stage of tertiary education); see UNESCO (2006).
} 
health dimension and "E" indicates dominance in the education dimension. The absence of the indicator(s) implies that there is no dominance in the relevant dimension(s). A gray cell indicates multidimensional dominance (MD), which is tested using definition (i) in Section 3. Note that the column totals for I, H, E, and MD yield the total number of times the column country is dominated by another country in each dimension (I, H, and E) and in the multidimensional analysis, respectively ${ }^{11}$ The corresponding row totals yield the total number of times a country is dominant in the three different dimensions and in the multidimensional analysis.

Table 5 shows the temporal FOD results in both the one-dimensional and the multidimensional analyses. For each row country, an "I", "H", and/or "E" in column 2 indicates that 2009 dominates 2005 in the relevant dimension(s). A gray cell indicates multidimensional dominance (MD) of 2009 over 2005. Similarly, the presence of one or more of these in column 3 indicates, for each row country, that 2013 dominates 2005, and so forth.

As seen from Tables 2 through 4, several spatial multidimensional dominances are identified. In 2005, 45 dominances are found (Table 2), whereas 40 and 43 dominances are found in 2009 and 2013, respectively (Tables 3 and 4 , respectively) ${ }^{12}$ The multidimensional dominances are largely driven by a few countries that either dominate several others or are dominated often. For example, in 2005 Germany dominates seven countries, Austria dominates six countries, and Portugal is dominated by 14 countries (Table 2). The dominated countries are most often southern European countries (Italy, Portugal, and Spain) and eastern European countries (Hungary, Lithuania, Latvia, Poland, and Slovenia), whereas the dominant countries are most often northern and western European countries (Austria, Germany, Ireland, the Netherlands, Sweden, and the United Kingdom). As mentioned, both the HDI (UNDP, 2014) and the MPI (Alkire and Apablaza, 2016) yield rankings where northern and western European countries are ranked higher than southern and eastern European countries. This is generally consistent with our findings ${ }^{13}$

The following dominances are persistent in all the spatial analyses (i.e., dominance in 2005, 2009, and 2013 is found): Austria, the United Kingdom, and Luxembourg persistently dominate Italy and Portugal; Germany dominates Estonia, Lithuania, Latvia, and Portugal; Estonia dominates Latvia; Ireland and the Nether-

\footnotetext{
${ }^{11}$ Since definition (i) in Section 3 uses weak inequalities rather than strict ones, a country will always dominate itself. For simplicity, these "self-dominances" are not included in Tables 2 through 4. nor in the remainder of the paper.

12 The maximum number of potential dominances for $k$ countries is $\left(k^{2}-k\right) / 2 . \quad k$ is raised to the second power to obtain all country combinations. The subtraction of $k$ in the nominator is to exclude self-dominance, whereas the 2 in the denominator is due to the fact that if country A dominates country B, B cannot dominate A. Since $k=24$ in this paper, the maximum number of potential dominances is $\left(24^{2}-24\right) / 2=276$.

${ }^{13}$ Note that the years of analysis in Alkire and Apablaza (2016) are 2006, 2009, and 2012, where only 2009 is somewhat directly comparable.
} 


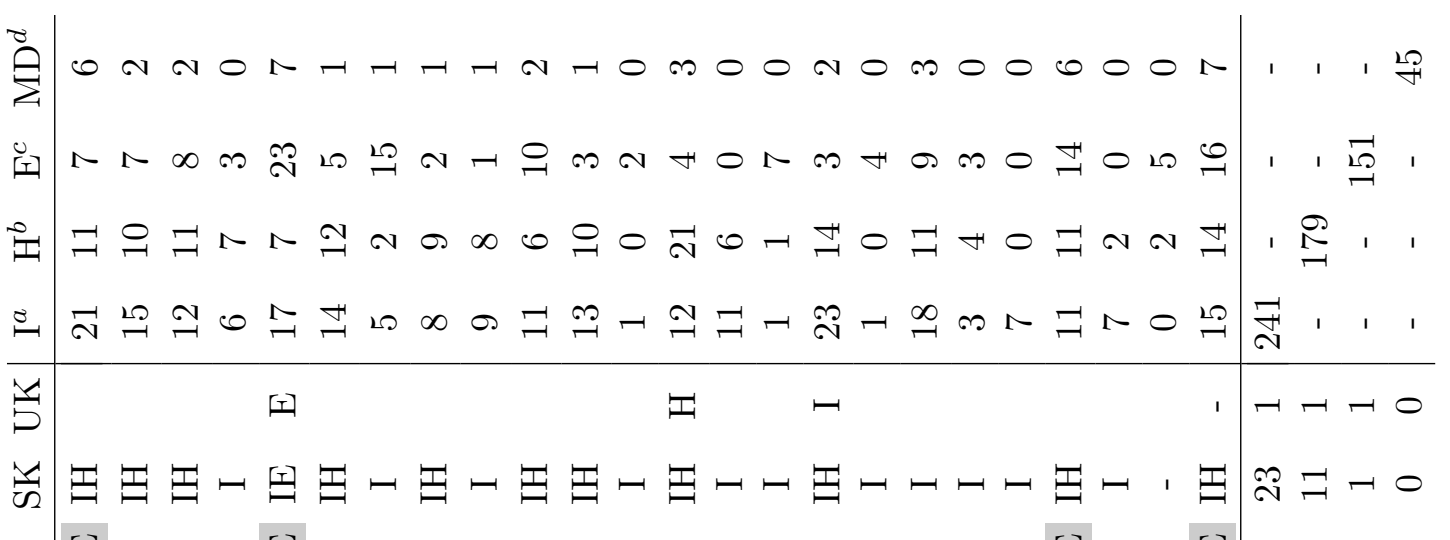

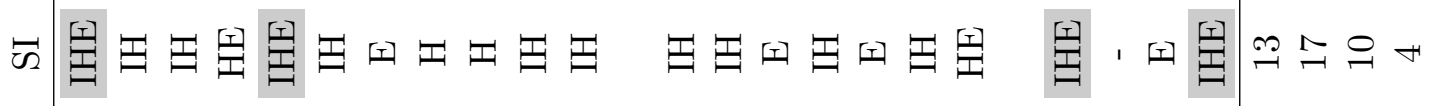

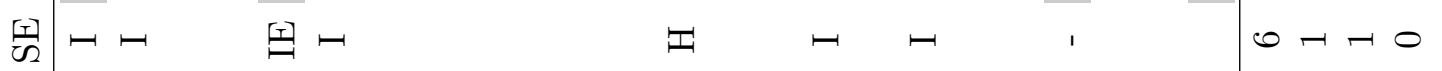

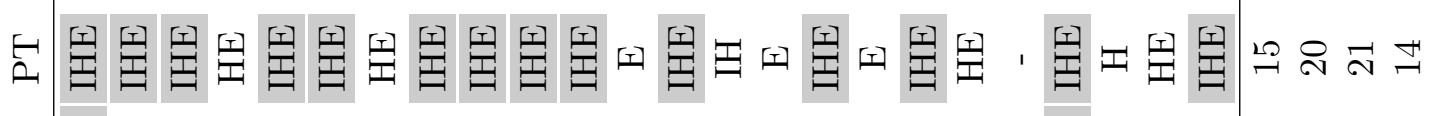

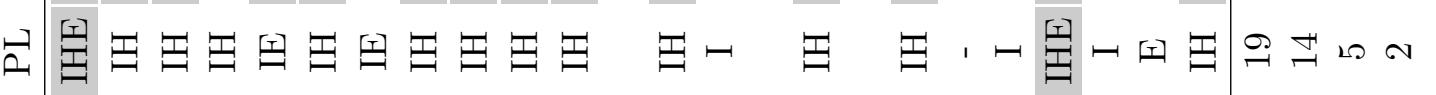
安一
되
曲
I $N \rightarrow N O$

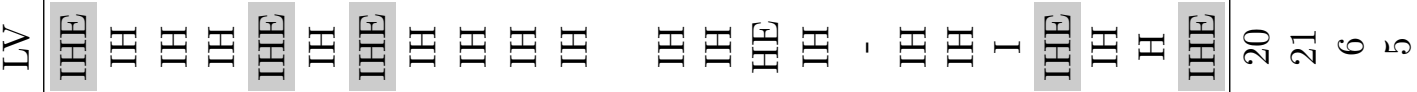

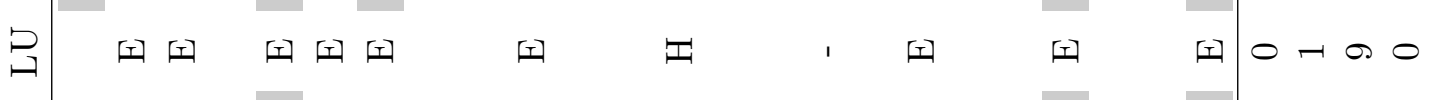

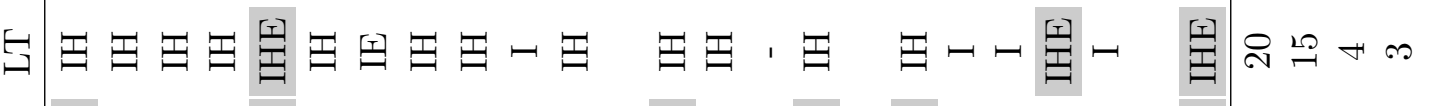

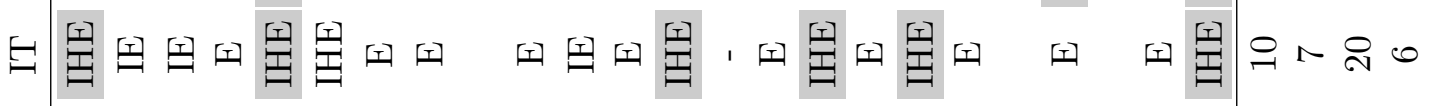

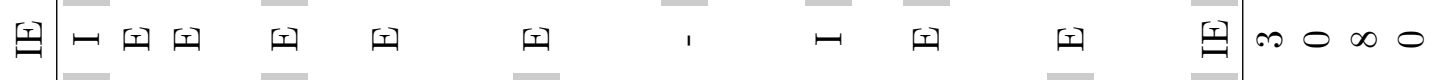

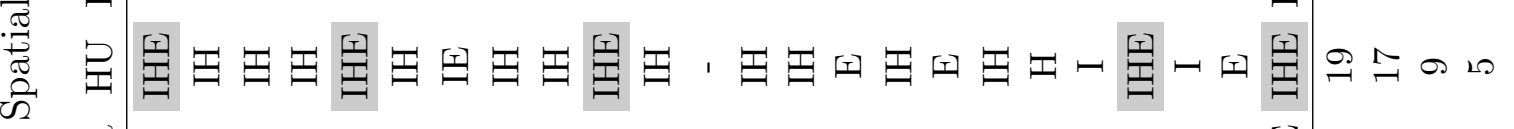
$\stackrel{\ddot{v}}{\frac{0}{0}}$
空国国国国国国
田、四四贸国
뙤
国 10

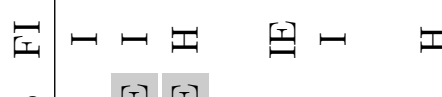
国画舅舅
国昰田

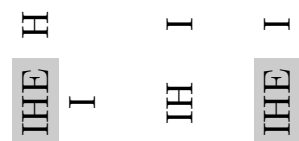
II $\infty \propto \sim 0$
国国国王
国国闰、咸
国一四四国
島
四
红灵寻寻 四
검

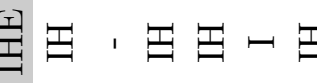
寻寻寻
田
四䒠落

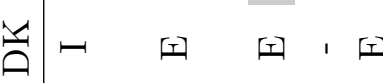
됨
도
$\begin{array}{lll} & \bullet & \Xi \\ \Xi & \Xi & \Xi\end{array}$
Ðコ
$\Xi \underset{\exists}{\infty} \stackrel{\infty}{\sim} \neg-$

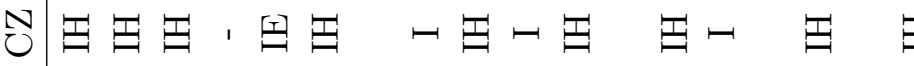

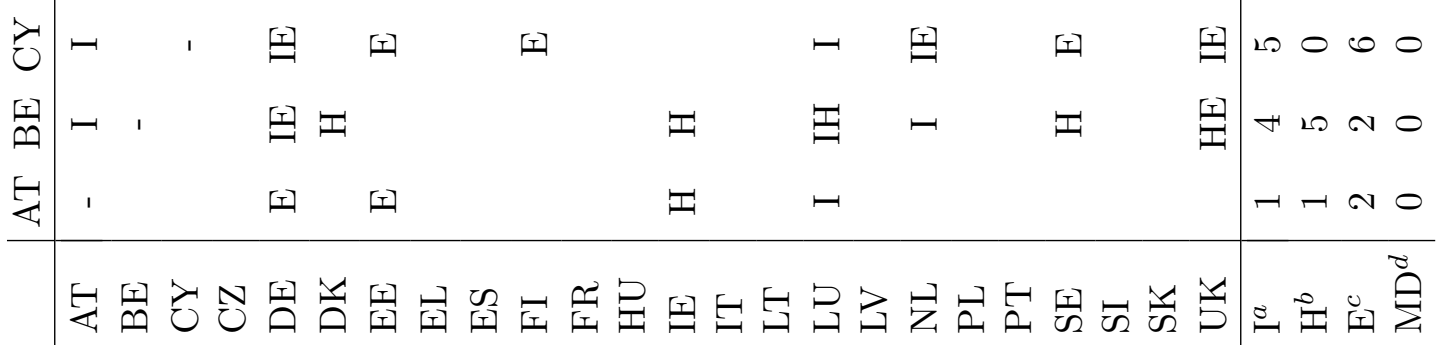

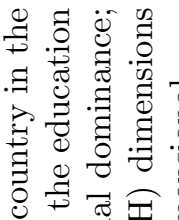

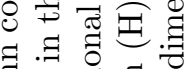

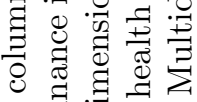

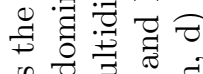

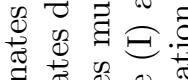

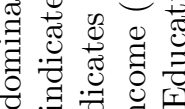

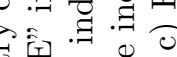

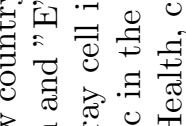

응 0.

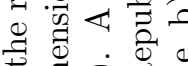

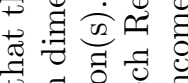

ज

记

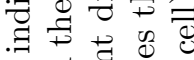

계유.

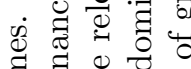

丞 寻

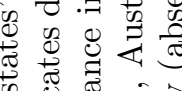

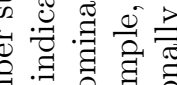

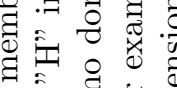

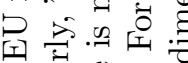

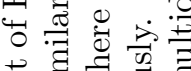

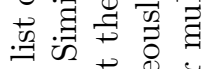

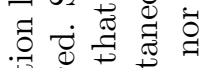

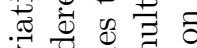

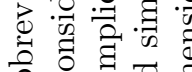

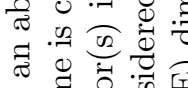

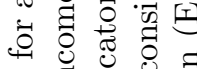

ㄱ..$\exists$

弟 司寻

牙 击

$\exists$ 의

0.

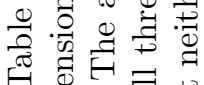

论

نे 荌. 


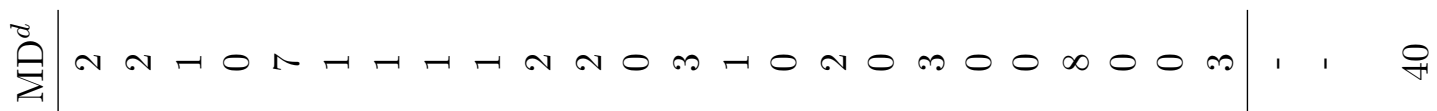

迕 N

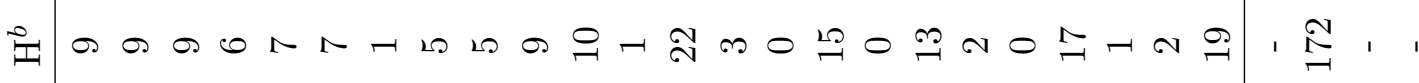

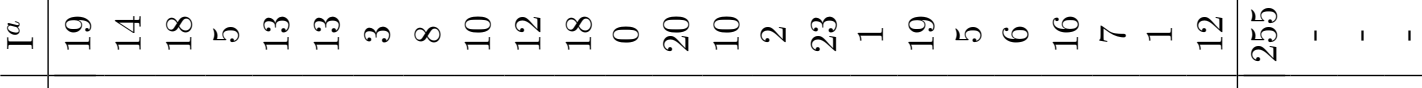

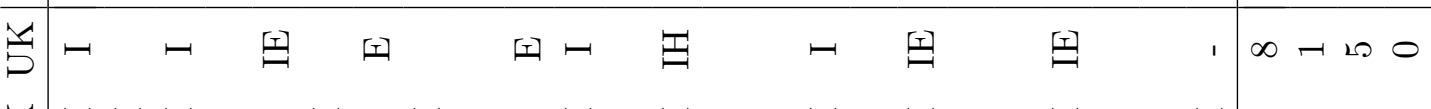

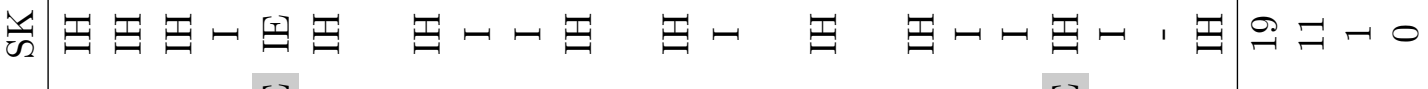

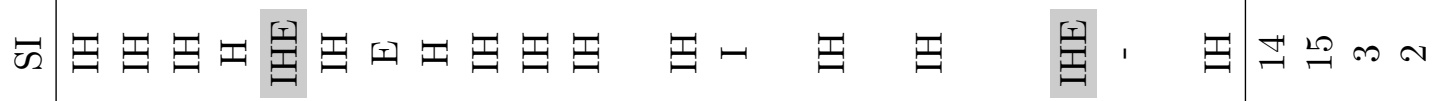

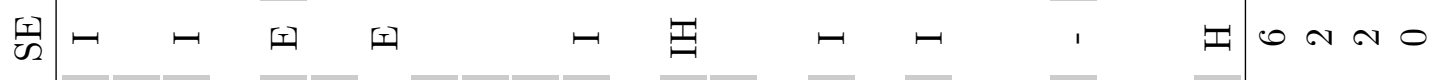

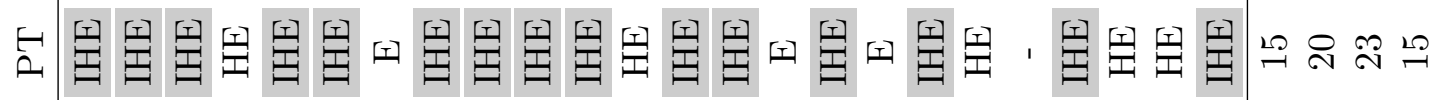

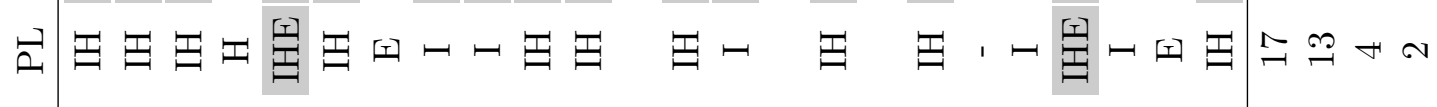

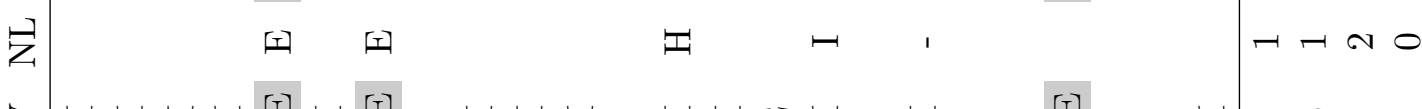

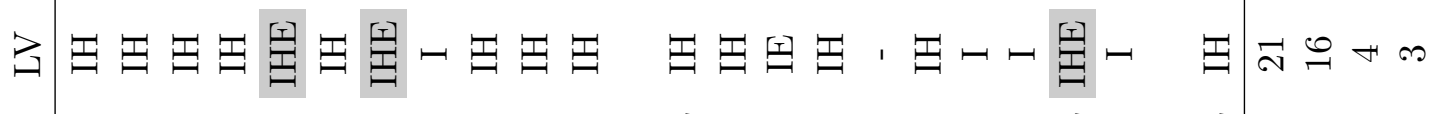

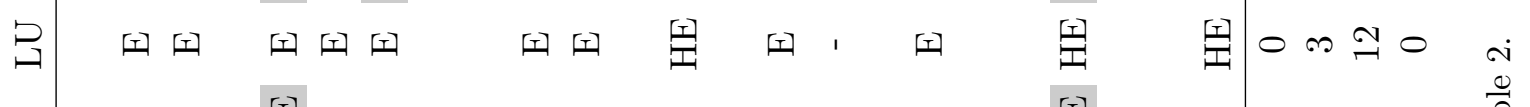

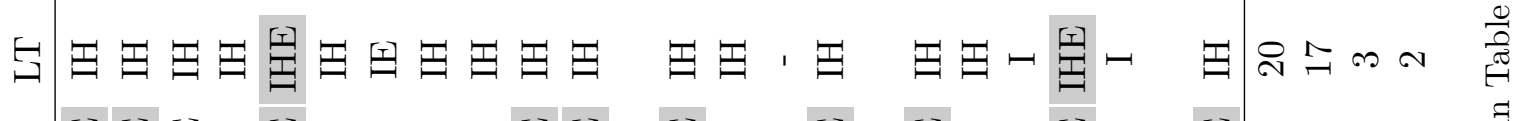

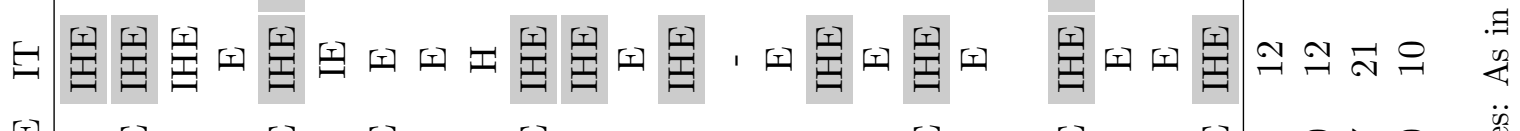

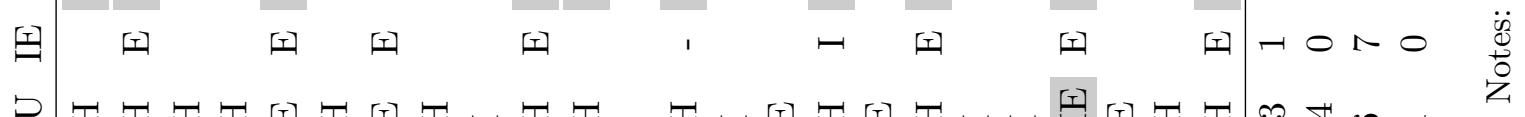

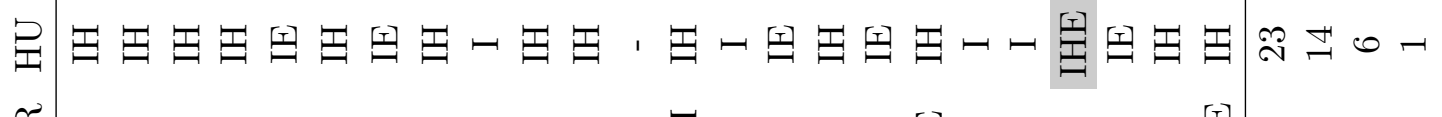

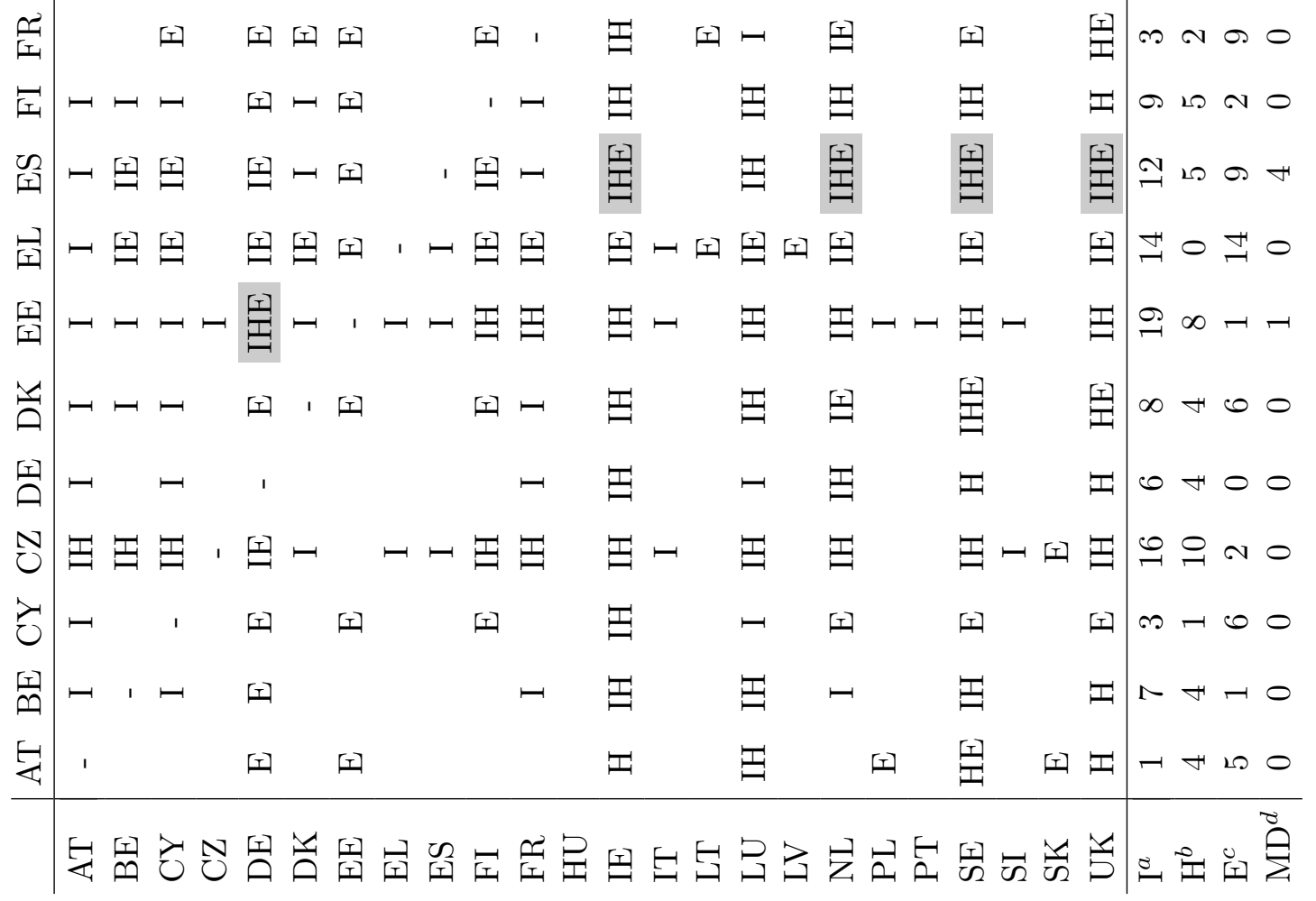




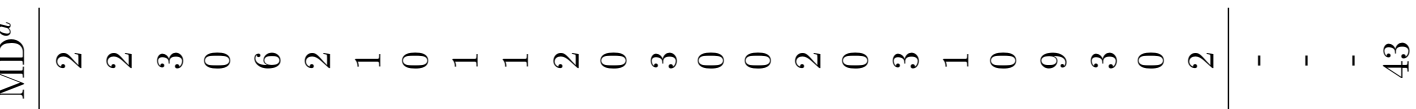

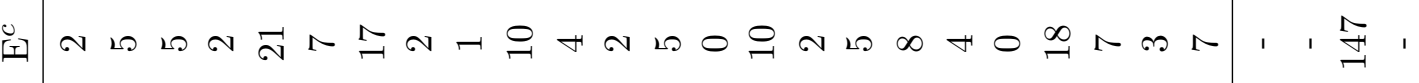

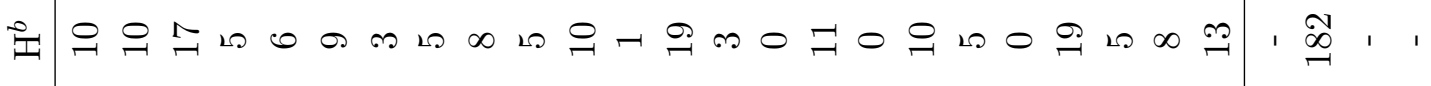

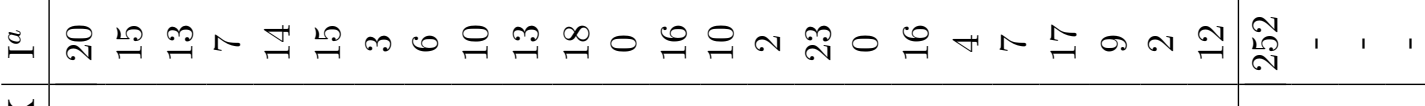

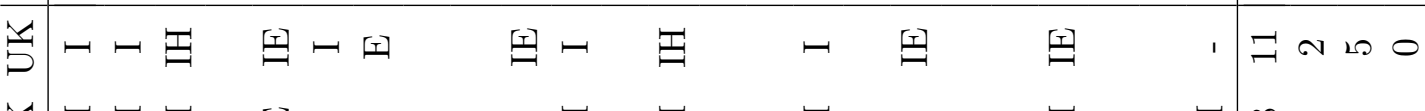

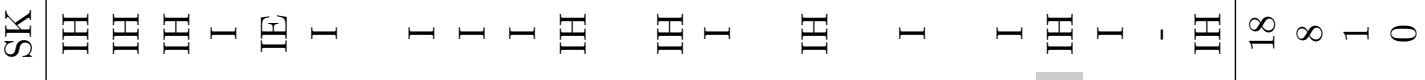

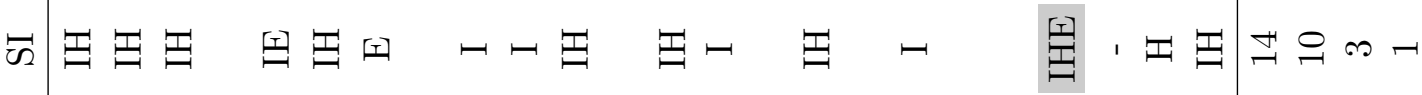

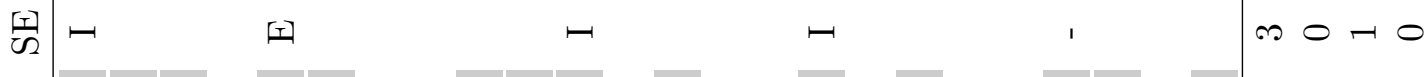

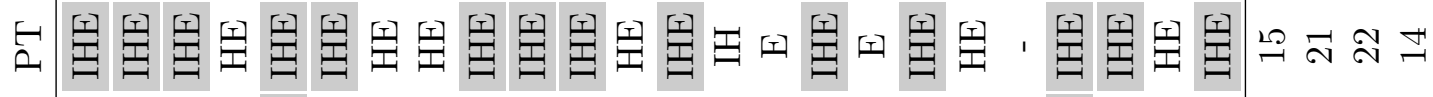

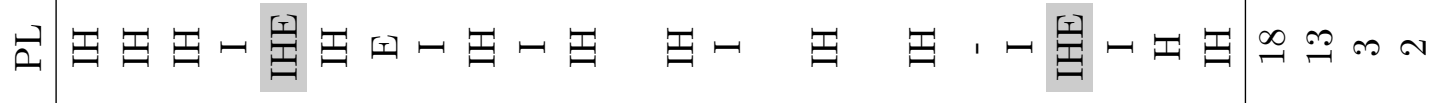

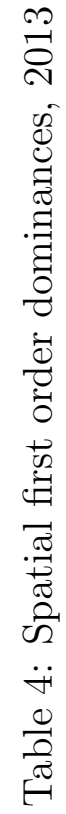

只

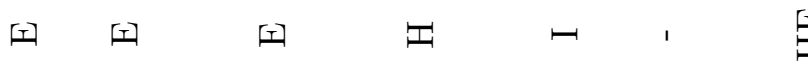

I I

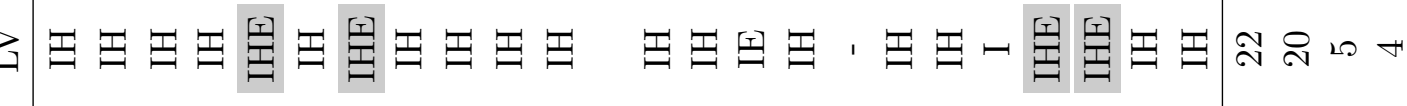

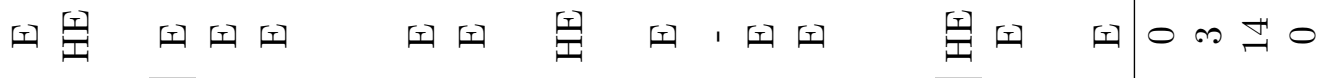

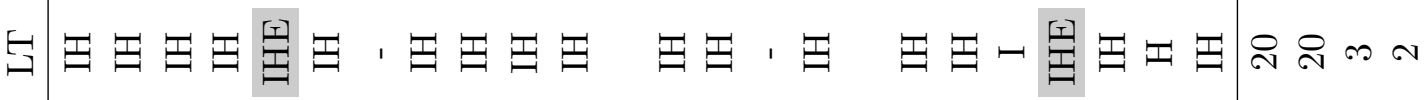

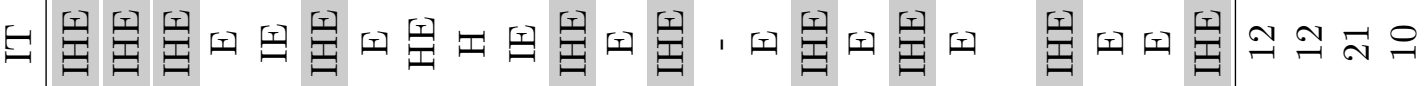

田

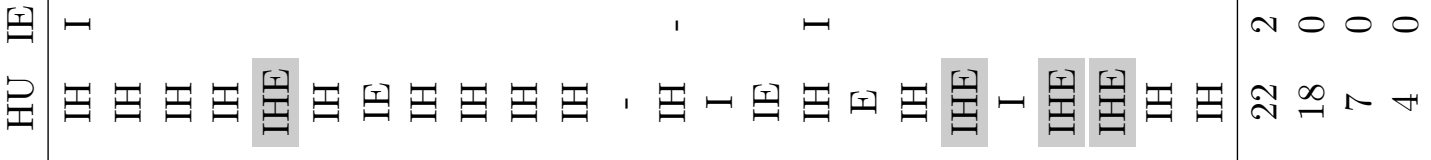

II

III $\rightarrow \infty \infty$

穴ーー 되

弪口国舅

国

国国国，国-

舅四叟

舅

$\infty-\infty 0$

तi

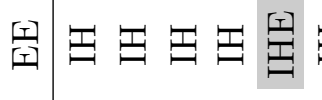

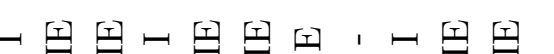

国・田・四国

䛼

国

穴

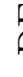

\section{次}

U

(6)

兵

田

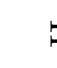

(1) 10

当思

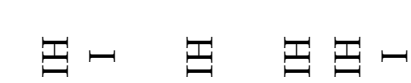

一国国

国祝。

1

田・サロロ

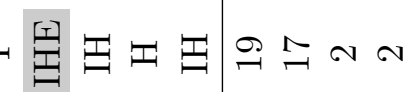

ヨ

$+1$

(1)

开

国

IN 20 Ho

I

a hoo

\begin{tabular}{|c|c|c|c|c|c|c|c|c|}
\hline$\Xi \Xi$ & $\mapsto \Xi$ & $\Xi ロ \Xi$ & $\Xi \curvearrowleft$ & & $\Xi$ & $\Xi$ & 寻ー寻寻 & $\stackrel{20}{\longrightarrow} \underset{\sim}{\sim} 00$ \\
\hline -1 & 臼臼四 & 되 & 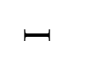 & 田 & $\mapsto$ & 国 & 国 & $00 \infty 0$ \\
\hline$\mp$ & 도 & $\mapsto$ & $\Xi$ & & $\mapsto$ & & $\Xi$ & $L \infty-0$ \\
\hline 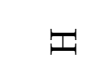 & 도 & & $\Psi$ & 도 & $\mapsto$ & [工工 & 国国田四 & $\neg \forall \wedge 0$ \\
\hline
\end{tabular}


Table 5: Temporal first order dominances

Deteriorations over time

Improvements over time

\begin{tabular}{|c|c|c|c|c|c|c|}
\hline & 05 dom 09 & 05 dom 13 & 09 dom 13 & 09 dom 05 & 13 dom 05 & 13 dom 09 \\
\hline $\mathrm{AT}$ & $\mathrm{IH}$ & $\mathrm{IH}$ & I & & $\mathrm{E}$ & $\mathrm{E}$ \\
\hline $\mathrm{BE}$ & & & & IE & IE & $\mathrm{HE}$ \\
\hline $\mathrm{CY}$ & & & I & IE & $\mathrm{E}$ & $\mathrm{HE}$ \\
\hline $\mathrm{CZ}$ & & & & IHE & IE & IE \\
\hline $\mathrm{DE}$ & & & & $\mathrm{HE}$ & $\mathrm{HE}$ & $\mathrm{E}$ \\
\hline DK & $\mathrm{H}$ & $\mathrm{H}$ & & $\mathrm{E}$ & $\mathrm{E}$ & IE \\
\hline $\mathrm{EE}$ & & & I & IE & IE & $\mathrm{E}$ \\
\hline EL & $\mathrm{H}$ & $\mathrm{IH}$ & I & $\mathrm{E}$ & $\mathrm{E}$ & $\mathrm{E}$ \\
\hline $\mathrm{ES}$ & & & I & IE & IE & $\mathrm{HE}$ \\
\hline FI & & & & IE & $\mathrm{IE}$ & $\mathrm{E}$ \\
\hline FR & & & & IE & IE & IE \\
\hline $\mathrm{HU}$ & & & I & IHE & $\mathrm{HE}$ & $\mathrm{E}$ \\
\hline IE & & $\mathrm{H}$ & $\mathrm{IH}$ & IE & IE & $\mathrm{E}$ \\
\hline IT & & I & I & IE & $\mathrm{E}$ & $\mathrm{E}$ \\
\hline $\mathrm{LT}$ & & & & IE & $\mathrm{IE}$ & $\mathrm{E}$ \\
\hline $\mathrm{LU}$ & $\mathrm{I}$ & $\mathrm{IH}$ & $\mathrm{I}$ & $\mathrm{E}$ & $\mathrm{E}$ & $\mathrm{E}$ \\
\hline $\mathrm{LV}$ & & & I & IHE & IHE & $\mathrm{E}$ \\
\hline NL & & & $\mathrm{IH}$ & IHE & $\mathrm{E}$ & $\mathrm{E}$ \\
\hline PL & & & I & IHE & IHE & $\mathrm{HE}$ \\
\hline $\mathrm{PT}$ & & & I & $\mathrm{HE}$ & $\mathrm{HE}$ & $\mathrm{E}$ \\
\hline $\mathrm{SE}$ & & & & IHE & IE & $\mathrm{E}$ \\
\hline SI & & I & I & $\mathrm{HE}$ & $\mathrm{HE}$ & $\mathrm{HE}$ \\
\hline SK & & & & I & IE & $\mathrm{E}$ \\
\hline UK & I & I & $\mathrm{IH}$ & $\mathrm{H}$ & & \\
\hline $\mathrm{I}^{a}$ & 3 & 6 & 15 & 16 & 12 & 3 \\
\hline $\mathrm{H}^{b}$ & 3 & 5 & 3 & 10 & 6 & 5 \\
\hline $\mathrm{E}^{c}$ & 0 & 0 & 0 & 21 & 23 & 23 \\
\hline $\mathrm{MD}^{d}$ & 0 & 0 & 0 & 3 & 2 & 0 \\
\hline
\end{tabular}

Notes: See Table C1 in Appendix C for an abbreviation list of EU member states' names. For each row country, an "I" in column 2 indicates that 2009 dominates 2005 in the income dimension; i.e., when only income is considered. An "I" in column 3 indicates that 2013 dominates 2005 and so forth. Similarly, "H" indicates dominance in the health dimension and "E" indicates dominance in the education dimension. The absence of the indicator(s) implies that there is no dominance in the relevant dimension(s). A gray cell indicates multidimensional dominance; i.e., when all three dimensions are considered simultaneously. For example, Belgium in 2013 dominates 2009 in the health $(\mathrm{H})$ and education (E) dimensions, but not in the income (I) dimension nor multidimensionally (absence of gray cell). a) Income, b) Health, c) Education, d) Multidimensional.

lands both dominate Spain, Italy, and Portugal; and Sweden dominates Hungary, Lithuania, Latvia, Poland, Portugal, and Slovenia. However, several dominances do change with the year of spatial analysis. For example, Belgium dominates Italy in both 2009 and 2013 but not in 2005, as is also the case for Sweden dominating Spain, the United Kingdom dominating Latvia in 2005 but not in 2009 and 2013, and so on.

The importance of multidimensional analyses of population welfare is well illus- 
trated by considering Table 2 and noting that, for example, Sweden dominates Spain in all three dimensions analyzed separately in 2005. However, in the multidimensional analysis, no dominance is found (as indicated by the absence of a gray cell). The same is the case in 2009 for Cyprus dominating Italy and Sweden dominating Denmark, and in 2013 for the United Kingdom dominating Spain in all three dimensions but not multidimensionally. This illustrates that dominance in all the included dimensions analyzed separately does not imply multidimensional dominance.

The Copeland scores (normalized to the interval $[-1 ; 1]$ ) associated with the spatial FOD analyses are shown in Table 6 with the countries being ranked accordingly. We observe that almost no northern or western European countries are in the bottom half of the ranking and that almost no southern and eastern European countries are in the top half of the ranking. In addition, the rankings seem largely consistent over time. For example, Germany and Sweden are consistently ranked first, second, or third, the Czech Republic and Slovakia have a Copeland score of zero in all three years, and Latvia, Italy, and Portugal are consistently ranked 21st, 23rd, and 24th, respectively.

Despite the importance of a multidimensional approach to welfare comparisons, some information can still be gained by the one-dimensional analyses, since onedimensional FOD is a necessary (though insufficient) condition for multidimensional FOD. The one-dimensional analyses can therefore give an indication about within which dimensions(s) a country is lagging behind. In the income dimension, the most dominant countries are clearly northern and western European countries; e.g., Luxembourg dominating all of the 23 other countries in all three years, Austria dominating between 19 and 21 countries in the three years, and so on. The southern and in particular eastern European countries are most often dominated in the income dimension; e.g., Hungary, Latvia, and Lithuania being dominated by 20 or more countries in 2013. When considering the health dimension, the pattern is mostly similar. For example, Lithuania, Latvia, and Portugal are all dominated by more than 20 countries in 2013. The countries most often dominated in the education dimension seem to be particularly southern European and only some eastern European countries, though Luxembourg is dominated 14 times in 2013. For example, Greece, Spain, Italy, and Portugal are dominated between 11 and 20 times in 2013 whereas Germany, Estonia, Finland, Lithuania, and Sweden all dominate ten or more countries in the same year.

The temporal FOD analyses yield five multidimensional dominances (Table 5), namely that 2009 dominates 2005 for the Czech Republic, and both 2009 and 2013 dominate 2005 for Latvia and Poland. Latvia and Poland have thus experienced a dominance improvement in multidimensional welfare in both 2009 and 2013 compared to 2005, whereas the improvement in the Czech Republic from 2005 to 2009 is 
Table 6: Copeland score and corresponding ranking of EU member states

\begin{tabular}{ccccccccc}
\multicolumn{7}{c}{2005} & \multicolumn{7}{c}{2009} \\
\hline Rank & Country & Score & Rank & Country & Score & Rank & Country & Score \\
\hline 1 & DE & 0.304 & 1 & SE & 0.348 & 1 & SE & 0.391 \\
1 & UK & 0.304 & 2 & DE & 0.304 & 2 & DE & 0.261 \\
3 & AT & 0.261 & 3 & IE & 0.130 & 3 & CY & 0.130 \\
3 & SE & 0.261 & 3 & NL & 0.130 & 3 & IE & 0.130 \\
5 & IE & 0.130 & 3 & UK & 0.130 & 3 & NL & 0.130 \\
5 & NL & 0.130 & 6 & AT & 0.087 & 6 & AT & 0.087 \\
7 & BE & 0.087 & 6 & BE & 0.087 & 6 & BE & 0.087 \\
7 & CY & 0.087 & 6 & FI & 0.087 & 6 & DK & 0.087 \\
7 & FI & 0.087 & 6 & FR & 0.087 & 6 & FR & 0.087 \\
7 & LU & 0.087 & 6 & LU & 0.087 & 6 & LU & 0.087 \\
11 & DK & 0.043 & 11 & CY & 0.043 & 6 & SI & 0.087 \\
11 & EL & 0.043 & 11 & DK & 0.043 & 6 & UK & 0.087 \\
11 & FR & 0.043 & 11 & EL & 0.043 & 13 & FI & 0.043 \\
14 & CZ & 0 & 14 & CZ & 0 & 14 & CZ & 0 \\
14 & EE & 0 & 14 & EE & 0 & 14 & EL & 0 \\
14 & SK & 0 & 14 & SK & 0 & 14 & SK & 0 \\
17 & PL & -0.087 & 17 & HU & -0.043 & 17 & EE & -0.043 \\
18 & LT & -0.130 & 18 & LT & -0.087 & 17 & PL & -0.043 \\
19 & ES & -0.174 & 18 & PL & -0.087 & 19 & LT & -0.087 \\
19 & SI & -0.174 & 18 & SI & -0.087 & 20 & ES & -0.130 \\
21 & HU & -0.217 & 21 & ES & -0.130 & 21 & HU & -0.174 \\
21 & LV & -0.217 & 21 & LV & -0.130 & 21 & LV & -0.174 \\
23 & IT & -0.261 & 23 & IT & -0.391 & 23 & IT & -0.435 \\
24 & PT & -0.609 & 24 & PT & -0.652 & 24 & PT & -0.609
\end{tabular}

Note: The Copeland scores are normalized to the interval $[-1 ; 1]$. If two or more countries have the same Copeland score, they are ordered alphabetically.

not persistent when comparing 2005 and 2013. Noticeably, no countries have experienced a multidimensional dominance deterioration in welfare over time (i.e., over the course of the financial and economic crisis). This is consistent with the HDI (UNDP, 2014) where no European country has experienced a lower HDI in 2013 compared to 2005.

The one-dimensional temporal results yield several dominances. In the income dimension, 2005 dominates 2009 and 2009 dominates 2013 (and, hence, 2005 dominates 2013 due to transitivity) for Austria, Luxembourg, and the United Kingdom. This implies that these countries have experienced an unambiguous deterioration of the income distribution over the entire time period. On the contrary, the Czech Republic and France have both experienced an unambiguous improvement in the income distribution over the entire time period, since 2013 dominates 2009 and 2009 dominates 2005 (again, this implies that 2013 dominates 2005 due to transitivity). 
Several changes in the income distribution between these two extremes occur - for example, Estonia experiencing an improvement in 2009 and 2013 compared to 2005 (2009 and 2013 dominate 2005) and a deterioration in 2013 compared to 2009 (2013 dominates 2009). As a last example, the Netherlands has experienced an improvement between 2005 and 2009 (2009 dominates 2005) but a deterioration between 2009 and 2013 (2013 dominates 2009). No clear pattern is present as to which European regions have experienced an unambiguous improvement or deterioration of the income distribution over the time period considered. Importantly, but not surprisingly, 15 countries have experienced a deterioration in the income distribution from 2009 to 2013, whereas only the Czech Republic, Denmark, and France have experienced an improvement. This is in contrast to the two other comparisons (2005 with 2009 and 2013, respectively), where 12 to 16 countries have experienced improvements and three to six countries have experienced a deterioration.

In the health dimension, Poland and Slovenia have experienced an unambiguous improvement, since 2013 dominates 2009 and 2009 dominates 2005. No countries have experienced an unambiguous deterioration over the entire time period. There is no clear geographical pattern with respect to improvements or deteriorations in the health distribution over the time period. The overall result for education is clearer: no country has experienced a deterioration in the education distribution, only improvements have occurred, with 21 out of the 24 countries experiencing unambiguous improvements over the entire time period. 2009 does not dominate 2005 for Austria and Slovakia; however, 2013 dominates both 2005 and 2009. The United Kingdom is the only exception since no improvements were found in the entire time period analyzed.

In general, there seems to have been a significant deterioration in the income distribution in European countries between 2009 and 2013, which is not surprising considering the financial and economic crisis. The number of countries experiencing improvements in health is largely constant, yet with a small decline between 2009 and 2013, and the same (large) number of countries are consistently experiencing an improvement in the distribution of education.

\section{Discussion}

A significant cross-country difference in self-reported health has been found in the literature. For example, Jürges (2007) finds that Denmark and Sweden tend to overrate their self-assessed health, whereas particularly France, Germany, Spain, and Italy tend to underrate it compared to a constructed index of the prevalence of chronic conditions and physical health measures. Focusing on dominances in the health dimension in Tables 2 through 4 , we cannot rule out that, for example, Den- 
mark dominating Spain in 2005 in the health dimension is due to Danes overrating their self-assessed health (and/or Spaniards underrating theirs). Whether or not this has an impact on the results is not evident. An underrating of health in, say, Italy may not necessarily mean that Italy is dominated by, say, Sweden in the health dimension. However, it is worth noting that Denmark and Sweden do not consistently dominate France, Germany, Spain, and Italy in the health dimension. These results do not yield clear evidence about whether or not the self-reported health measure is adequate in describing population health. It does, however, indicate that no clear trend is found across all countries.

Though the FOD approach is theoretically well founded, a few empirical limitations are worth noting. First, as discussed in Section 3 , the FOD approach, and other robust methods that do not rely on a weighting scheme, may yield an indeterminate result where no dominance is found when comparing two countries. For example, 43 out of the potential 276 dominances are found in 2013 (Table 4). This provides limited information about the relative welfare of all the populations and makes us unable to obtain a complete ranking of all EU member states, unlike what can be found using the HDI and the MPI. As shown in Section 5, the Copeland (1951) method can be used as a measure of the tendency to outperform other countries as an overall relative indicator of population well-being (Arndt et al., 2016). However, this does not guarantee a complete ranking as in the present paper, where some countries have the same Copeland score. But the dominances we do observe are the only comparisons that provide unambiguous proof that the dominant country is better off than the dominated. A complete ranking obtained by alternative methods, although convenient, is obtained due to the additional assumptions underlying these methods and/or the assumptions about the dimensions.

Second, the FOD approach provides no information about whether a dominant distribution is marginally or substantially better than the dominated distribution. For example, our finding that the Netherlands dominates Italy in 2013 provides no information about whether the welfare distribution in the Netherlands is much better or only slightly better than the welfare distribution in Italy. One can use bootstrapping to obtain an empirical probability of observing dominances under re-sampling to mitigate this limitation (Arndt et al., 2012).

Third, some dimensions that have been shown to have an impact on individuals' well-being (and hence on population welfare) cannot be included in a FOD analysis. For example, Delhey (2004) shows that besides income, education, and health, dimensions such as partnership and employment status are significant in explaining life satisfaction for individuals in European countries after controlling for characteristics such as gross domestic product (GDP) per capita, political freedom, and more. However, partnership may not be suitable in a FOD analysis since the dimension is 
not ordinal in nature. One cannot say that being single is worse (or better) than having a partner.

As with any measure of welfare using non-continuous indicators, FOD is sensitive to the threshold(s) between levels. ${ }^{14}$ However, the inclusion of multi-level indicators mitigates this sensitivity 15 As an example, consider Greece and Spain and the single indicator in the health dimension in Table 2. Greece does not dominate Spain, nor does Spain dominate Greece. However, consider aggregating the health dimension's five levels into a binary indicator. Suppose that we I) aggregate being in very bad, bad, and fair health into ill health, and being in good and very good health into decent health, or II) aggregate being in very bad, and bad health into ill health, and being in fair, good, and very good health into decent health. The only difference between I and II is thus that fair health is included in ill health in the former and in decent health in the latter. When we use the aggregation in I, the shares of the population in the two categories are 0.2318 in ill health and 0.7682 in decent health in Greece and 0.2564 in ill health and 0.7436 in decent health in Spain. Hence, Greece dominates Spain. On the contrary, using the aggregation in II, the share of the population in the two categories are 0.0877 in ill health and 0.9123 in decent health in Greece and 0.0680 in ill health and 0.9320 in decent health in Spain. Hence, Spain dominates Greece; i.e., the conclusion is reversed. Different threshold(s) between levels can thus alter conclusions about population welfare rankings. A finer subdivision of indicators because of the inclusion of multilevel indicators (as opposed to binary indicators) will thus lower the risk of threshold choices impacting results. Appendix $\mathrm{D}$ shows the multidimensional FOD analyses using binary indicators rather than the multi-level ones used in Section 5 .

\section{Conclusion}

We compare multidimensional welfare in EU member states before, during, and after the financial crisis both spatially and temporally using first order dominance (FOD) on multi-level indicators. Implicitly or explicitly, weighting schemes are used in most multidimensional analyses of welfare. Our approach enables us to make comparisons of multidimensional population welfare that are robust to different weighting schemes. We add to the existing literature by using multi-level indicators of dimensions thus avoiding simplified welfare comparisons relying on binary indicators. In addition, the use of multi-level indicators of dimensions mitigates one of the challenges common to all welfare methods using non-continuous indica-

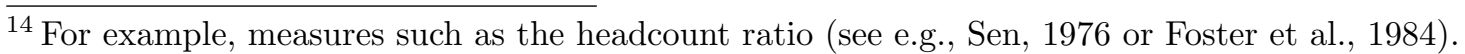

${ }^{15}$ Though in a slightly different set-up, see also Hussain et al. (2016) for an example of refining dimensions to analyze the "depth" of FOD.
} 
tors, namely that they are sensitive to the thresholds between levels. We add to the scarce literature applying FOD on developed countries, and we stress the importance of multidimensional welfare analyses since dominance in each single dimension is merely a necessary but insufficient condition for multidimensional dominance.

Several dominances between European member states are found in all the three years analyzed. These are largely driven by relatively few countries which either dominate or are dominated by quite a few other countries. In particular, the dominated countries are most often southern and eastern EU member states, whereas the dominant countries are most often northern and western European member states. This is consistent with the existing literature. The ranking of countries using the Copeland method does not vary much in the three years analyzed. Northern and western European countries are consistently ranked higher than southern and eastern European countries. We find that only a few countries have experienced temporal multidimensional improvements in welfare, namely the Czech Republic, Latvia, and Poland, and that no countries have experienced an unambiguous deterioration. Thus, while the financial and economic crisis has had major impacts on especially income both at the individual and country level, the populations' broadly defined welfare has not unambiguously deteriorated over time.

\section{References}

Alkire, S. (2002). Dimensions of human development. World Development 30(2), $181-205$.

Alkire, S. and M. Apablaza (2016). Multidimensional poverty in Europe 2006-2012: illustrating a methodology. OPHI Working Paper No. 74. University of Oxford.

Alkire, S., M. Apablaza, and E. Jung (2014). Multidimensional poverty measurement for EU-SILC countries. OPHI Research in Progress 36c. Oxford University.

Alkire, S. and J. Foster (2011a). Counting and multidimensional poverty measurement. Journal of Public Economics 95(7-8), 476-487.

Alkire, S. and J. Foster (2011b). Understandings and misunderstandings of multidimensional poverty measurement. Journal of Economic Inequality 9(2), 289-314.

Alkire, S., J. Foster, S. Seth, M. E. Santos, J. M. Roche, and P. Ballon (2015). Multidimensional Poverty Measurement and Analysis. Oxford: Oxford University Press.

Arndt, C., R. Distante, M. A. Hussain, L. P. Østerdal, P. L. Huong, and M. Ibraimo (2012). Ordinal welfare comparisons with multiple discrete indicators: a first order 
dominance approach and application to child poverty. World Development $40(11)$, 2290-2301.

Arndt, C., M. A. Hussain, S. Vincenzo, F. Tarp, and L. P. Østerdal (2016). Poverty mapping based on first-order dominance with an example from Mozambique. Journal of International Development 28(1), 3-21.

Arndt, C. and F. Tarp (2017). Measuring Poverty and Wellbeing in Developing Countries. Oxford: Oxford University Press.

Arrow, J. K. (1971). A utilitarian approach to the concept of equality in public expenditures. The Quarterly Journal of Economics 85(3), 409-415.

Atkinson, A. B. (1992). Measuring poverty and differences in family composition. Economica 59(233), 1-16.

Atkinson, A. B. and F. Bourguignon (1982). The comparison of multi-dimensioned distributions of economic status. The Review of Economic Studies 49(2), 183-201.

Atkinson, A. B. and F. Bourguignon (1987). Income distribution and differences in need. In G. R. Feiwek (Ed.): Arrow and the Foundations of the Theory of Economic Policy. London, UK: Harvester Wheatsheaf.

Bossert, W., S. R. Chakravarty, and C. D'Ambrosio (2013). Multidimensional poverty and material deprivation with discrete data. Review of Income and Wealth 59(1), 29-43.

Bourguignon, F. (1989). Family size and social utility: income distribution dominance criteria. Journal of Econometrics 42(1), 67-80.

Bourguignon, F. and S. R. Chakravarty (2003). The measurement of multidimensional poverty. The Journal of Economic Inequality 1(1), 25-49.

Copeland, A. H. (1951). A "reasonable" social welfare function. University of Michigan Seminar on Applications of Mathematics to the Social Sciences.

De Beer, P. (2012). Earnings and income inequality in the EU during the crisis. International Labor Review 151(4), 313-331.

Delhey, J. (2004). Quality of life in Europe. Life satisfaction in an enlarged Europe. Office for Official Publications of the European Commission, Luxemburg. European Foundation for the Improvement of Living and Working Conditions.

Duclos, J.-Y. and D. Échevin (2011). Health and income: a robust comparison of Canada and the US. Journal of Health Economics 30(2), 293-302. 
Duclos, J.-Y., D. E. Sahn, and S. D. Younger (2006). Robust multidimensional poverty comparisons. The Economic Journal 116(514), 943-968.

Duclos, J.-Y., D. E. Sahn, and S. D. Younger (2007). Robust multidimensional poverty comparisons with discrete indicators of well-being. In S. P. Jenkins and J. Micklewright (Eds.): Inequality and Poverty Re-examined. Oxford: Oxford University Press.

Dyckerhoff, R. and K. Mosler (1997). Orthant orderings of discrete random vectors. Journal of Statistical Planning and Inference 62(2), 193-205.

European Commission (2009). Economic Crisis in Europe: Causes, Consequences and Cesponses. European Economy 7. http://ec.europa.eu/economy_ finance/publications/pages/publication15887_en.pdf, downloaded February 10, 2017.

European Union (2011). Interinstitutional Style Guide. http://bookshop. europa.eu/en/interinstitutional-style-guide-2011-pb0A3110655/ ?CatalogCategoryID=9.EKABstN84AAAEjuJAY4e5L, downloaded October 28,2015 .

Foster, J., J. Greer, and E. Thorbecke (1984). A class of decomposable poverty measures. Econometrica 52(3), 761-766.

Gravel, N., P. Moyes, and B. Tarroux (2009). Robust international comparisons of distributions of disposable income and regional public goods. Economica 76 (303), $432-461$.

Gravel, N. and A. Mukhopadhyay (2010). Is India better off today than 15 years ago? A robust multidimensional answer. Journal of Economic Inequality 8(2), $173-195$.

Hagenaars, A. J., K. De Vos, and M. A. Zaidi (1996). Poverty statistics in the late 1980s: research based on micro-data. Luxembourg: Office for Official Publications of the European Communities, Eurostat.

Higham, N. J. (2002). Accuracy and Stability of Numerical Algorithms. Philadelphia: Society for Industrial and Applied Mathematics.

Hussain, M. A. (2016). EU country rankings' sensitivity to the choice of welfare indicators. Social Indicators Research 125(1), 1-17.

Hussain, M. A., M. M. Jørgensen, and L. P. Østerdal (2016). Refining population health comparisons: a multidimensional first order dominance approach. Social Indicators Research 129(2), 1-21. 
Jürges, H. (2007). True health vs response styles: exploring cross-country differences in self-reported health. Health Economics 16(2), 163-178.

Kamae, T., U. Krengel, and G. L. O'Brien (1977). Stochastic inequalities on partially ordered spaces. The Annals of Probability 5(6), 899-912.

Kentikelenis, A., M. Karanikolos, I. Papanicolas, S. Basu, M. McKee, and D. Stuckler (2011). Health effects of financial crisis: omens of a Greek tragedy. The Lancet 378(9801), 1457-1458.

Kolm, S. (1977). Multidimensional egalitarianism. The Quarterly Journal of Economics $91(1), 1-13$.

Lehmann, E. L. (1955). Ordered families of distributions. The Annals of Mathematical Statistics 26(3), 399-419.

Levhari, D., J. Paroush, and B. Peleg (1975). Efficiency analysis for multivariate distributions. Review of Economic Studies 42(1), 87-91.

Mosler, K. C. and M. R. Scarsini (1991). Stochastic Orders and Decision Under Risk. Heyward, California: Institute of Mathematical Statistics.

Muller, C. and A. Trannoy (2011). A dominance approach to the appraisal of the distribution of well-being across countries. Journal of Public Economics 95(3-4), 239-246.

OECD (2013). Education Indicators in Focus. Chapter B: Financial and human resources invested in education. What is the impact of the economic crisis on public education spending? https://www.oecd.org/edu/skills-beyond-school/, downloaded February 3, 2017.

Østerdal, L. P. (2010). The mass transfer approach to multivariate discrete first order stochastic dominance: direct proof and implications. Journal of Mathematical Economics 46(6), 1222-1228.

Range, T. M. and L. P. Østerdal (2016). First order dominance: stronger characterization and a bivariate checking algorithm. Draft, October 2016. https: //sites.google.com/site/lposterdal/, downloaded June 15, 2017.

Ravallion, M. (2011). On multidimensional indices of poverty. The Journal of Economic Inequality 9(2), 235-248.

Ravallion, M. (2012). Mashup indices of development. The World Bank Research Observer 27(1), 1-32. 
Sampson, A. R. and L. R. Whitaker (1988). Positive dependence, upper sets, and multidimensional partitions. Mathematics of Operations Research 13(2), 254-264.

Sen, A. K. (1970). Collective Choice and Social Welfare. San Francisco: HoldenDay.

Sen, A. K. (1973). On Economic Inequality. New York: Oxford University Press.

Sen, A. K. (1976). Poverty: an ordinal approach to measurement. Econometrica $44(2), 219-231$.

Sen, A. K. (1985). Commodities and Capabilities. Amsterdam: North Holland.

Shaked, M. and J. G. Shanthikumar (2007). Stochastic Orders. New York: Springer Science and Business Media.

Siersbæk, N., L. P. Østerdal, and C. Arndt (2017). Multidimensional first order dominance comparisons of population wellbeing. In C. Arndt and F. Tarp (Eds.): Measuring Poverty and Wellbeing in Developing Countries. Oxford: Oxford University Press.

Strassen, V. (1965). The existence of probability measures with given marginals. Annals of Mathematical Statistics 36(2), 423-439.

Stuckler, D., S. Basu, M. Suhrcke, A. Coutts, and M. McKee (2009). The public health effect of economic crises and alternative policy responses in Europe: an empirical analysis. The Lancet 374(9686), 315-323.

UNDP (1990). Human Development Report 1990 - Concept and Measurement of Human Development. United Nations Development Programme. http://hdr. undp.org/en/global-reports, downloaded May 29th, 2017.

UNDP (2014). Human Development Report 2014 - Sustaining Human Progress: Reducing Vulnerabilities and Building Resilience. United Nations Development Programme. http://hdr.undp.org/en/global-reports, downloaded February 12 th, 2016.

UNESCO (2006). ISCED 1997: International Standard Classification of Education. http://www.uis.unesco.org/Library/Documents/isced97-en.pdf, downloaded January 19th, 2016.

Whelan, C. T., B. Nolan, and B. Maître (2014). Multidimensional poverty measurement in Europe: an application of the adjusted headcount approach. Journal of European Social Policy 24(2), 183-197. 
World Bank (1990). World Development Report 1990: Poverty. New York: Oxford University Press.

\section{Appendix A. Sample sizes}

Table A1: Samples sizes for EU-SILC data

\begin{tabular}{lcccccc}
\multicolumn{2}{c}{2005} & \multicolumn{2}{c}{2009} & \multicolumn{2}{c}{2013} \\
\hline Country $^{a}$ & No. obs. & Percent & No. obs. & Percent & No. obs. & Percent \\
\hline AT & 10,413 & 2.95 & 11,049 & 3.06 & 10,938 & 3.15 \\
BE & 9,966 & 2.82 & 11,652 & 3.23 & 11,592 & 3.34 \\
CY & 8,997 & 2.55 & 7,553 & 2.09 & 10,980 & 3.16 \\
CZ & 7,826 & 2.21 & 16,829 & 4.67 & 11,602 & 3.34 \\
DE & 24,976 & 7.08 & 23,824 & 6.61 & 22,540 & 6.49 \\
DK & 5,956 & 1.68 & 5,866 & 1.62 & 5,429 & 1.56 \\
EE & 9,643 & 2.73 & 8,724 & 2.42 & 10,106 & 2.91 \\
EL & 12,381 & 3.51 & 15,045 & 4.17 & 15,318 & 4.41 \\
ES & 30,276 & 8.58 & 30,418 & 8.44 & 26,429 & 7.61 \\
FI & 10,904 & 3.09 & 9,952 & 2.76 & 10,756 & 3.1 \\
FR & 18,749 & 5.31 & 20,102 & 5.58 & 20,563 & 5.92 \\
HU & 14,663 & 4.15 & 20,380 & 5.65 & 21,270 & 6.13 \\
IE & 12,030 & 3.41 & 9,898 & 2.74 & 9,442 & 2.72 \\
IT & 47,311 & 13.41 & 42,657 & 11.84 & 36,612 & 10.55 \\
LT & 9,919 & 2.81 & 9,518 & 2.64 & 8,195 & 2.36 \\
LU & 7,525 & 2.13 & 8,623 & 2.39 & 7,996 & 2.30 \\
LV & 7,913 & 2.24 & 12,066 & 3.35 & 12,112 & 3.49 \\
NL & 9,347 & 2.65 & 9,724 & 2.69 & 10,102 & 2.91 \\
PL & 37,671 & 10.68 & 29,229 & 8.11 & 27,804 & 8.01 \\
PT & 10,702 & 3.03 & 11,101 & 3.08 & 14,008 & 4.03 \\
SE & 6,035 & 1.71 & 7,538 & 2.09 & 6,084 & 1.75 \\
SI & 8,287 & 2.34 & 9,282 & 2.57 & 9,001 & 2.59 \\
SK & 12,877 & 3.65 & 13,773 & 3.82 & 13,220 & 3.81 \\
UK & 18,282 & 5.18 & 15,350 & 4.26 & 14,855 & 4.28 \\
\hline Total ${ }^{b}$ & 352,649 & 100.00 & 360,153 & 100.00 & 346,954 & 100.00
\end{tabular}

Notes: For each row country, the numbers in columns 2, 4, and 6 indicate the sample sizes (number of observations) in the EU-SILC data in 2005, 2009, and 2013, respectively. Similarly, for each row country, columns 3, 5, and 7 indicate the percent of total observations in 2005, 2009, and 2013, respectively. a) See Table C1 in Appendix C for an abbreviation list of EU member states. b) Difference in total of percentages due to rounding. 


\section{Appendix B. Data structure}

Table B1: Example of data structure using sample data for Germany in 2005.

Education $=1$

\begin{tabular}{ccccccc|c}
\hline & \multicolumn{7}{c}{ Health } \\
& & 1 & 2 & 3 & 4 & 5 & Total \\
Income & 1 & 0.06 & 0.28 & 0.73 & 0.63 & 0.28 & 1.98 \\
& 2 & 0.13 & 0.61 & 1.78 & 1.95 & 0.79 & 5.27 \\
& 3 & 0.13 & 0.52 & 1.79 & 2.55 & 1.10 & 6.09 \\
& 4 & 0.14 & 0.30 & 1.09 & 1.95 & 1.17 & 4.65 \\
\cline { 2 - 7 } & Total & 0.46 & 1.71 & 5.39 & 7.09 & 3.34 & 17.99 \\
\hline
\end{tabular}

\begin{tabular}{ccccccc|c}
\hline \hline \multicolumn{7}{c}{ Education $=2$} \\
\hline \multirow{6}{*}{ Income } & \multicolumn{7}{c}{ Health } \\
& & 1 & 2 & 3 & 4 & 5 & Total \\
& 1 & 0.11 & 0.49 & 1.15 & 1.33 & 0.28 & 3.36 \\
& 2 & 0.18 & 1.14 & 3.82 & 4.70 & 1.18 & 11.01 \\
& 3 & 0.21 & 1.20 & 5.68 & 8.47 & 2.14 & 17.70 \\
& 4 & 0.14 & 0.87 & 4.84 & 8.71 & 2.96 & 17.53 \\
\cline { 2 - 8 } & Total & 0.65 & 3.70 & 15.49 & 23.20 & 6.55 & 49.60 \\
& & & & & & & \\
\hline \hline
\end{tabular}

Education $=3$

\begin{tabular}{llccccc|c}
\hline & \multicolumn{7}{c}{ Health } \\
& & 1 & 2 & 3 & 4 & 5 & Total \\
\multirow{4}{*}{ Income } & 1 & 0.05 & 0.20 & 0.43 & 0.65 & 0.14 & 1.47 \\
& 2 & 0.13 & 0.41 & 1.44 & 1.83 & 0.45 & 4.26 \\
& 3 & 0.10 & 0.62 & 2.93 & 4.54 & 1.02 & 9.22 \\
& 4 & 0.11 & 0.79 & 4.36 & 9.40 & 2.80 & 17.46 \\
\cline { 2 - 8 } & Total & 0.38 & 2.03 & 9.17 & 16.42 & 4.41 & 32.42 \\
Sum $^{a}$ & & & & & & & \\
& & & & & & & 100.00
\end{tabular}

Notes: Percentage of the German population in the 60 different outcomes in 2005 as estimated using the sample from EU-SILC. a) Sum of the three sum of totals (17.99, 49.60, and 32.42). Difference due to rounding. 


\section{Appendix C. Abbreviation list}

Table C1: Abbreviation list, included EU member states

\begin{tabular}{ll} 
Abbreviation & Country \\
\hline AT & Austria \\
BE & Belgium \\
CY & Cyprus \\
CZ & Czech Republic \\
DE & Germany \\
DK & Denmark \\
EE & Estonia \\
EL & Greece \\
ES & Spain \\
FI & Finland \\
FR & France \\
HU & Hungary \\
IE & Ireland \\
IT & Italy \\
LT & Lithuania \\
LU & Luxembourg \\
LV & Latvia \\
NL & Netherlands \\
PL & Poland \\
PT & Portugal \\
SE & Sweden \\
SI & Slovenia \\
SK & Slovakia \\
UK & United Kingdom
\end{tabular}

Notes: In line with the EU abbreviations rules, we use the two letter ISO code (ISO 3166 alpha-2) as abbrevations except for a) EL instead of GR for Greece, and b) UK instead of GB for the United Kingdom (Great Britain and Northern Ireland) (European Union, 2011, section 7.1.1.). 


\section{Appendix D. Binary FOD analyses}

As mentioned, applications of FOD in a welfare context have until now used binary indicators. To show the consequences of using multi-level indicators instead of binary ones, analyses similar to those in Section 5 but using binary indicators have been conducted. Instead of applying the multi-level indicators outlined in Table 1, we combine the levels into binary outcomes as shown in Table D1, where the second column from the right shows the multi-level indicators applied in the previously reported results, and the rightmost column shows how the multi-level indicators are aggregated into binary indicators ${ }^{16}$

Table D1: Description of welfare dimensions and binary indicators

\begin{tabular}{llll} 
Dimension & Indicator & Multi-level & Binary \\
\hline Income & Equivalized & 1 & \\
& annual net & 2 & 1 \\
& income & 3 & $\{2$ \\
\hline \multirow{2}{*}{ Health } & Self-reported & 1 & \\
& health & 2 & $\{1$ \\
& & 3 & $\{2$ \\
\hline \multirow{2}{*}{ Education } & Highest ISCED & 1 & \\
& level obtained & 2 & $\{1$ \\
& & 3 & $\{2$
\end{tabular}

Note: See Table 1 for further information.

The results are shown in Tables D2 through D5. These are the analogous of Tables 2 through 5, the only difference being that the results are obtained using the binary indicators described Table D1. Naturally, the multidimensional binary analyses yield several more dominances than the corresponding multidimensional multi-level analyses ${ }^{17}$ In particular, we never obtain an indeterminate result in each dimension analyzed separately since the distribution in a given dimension is fully described by a single number, e.g. those who are worse off. In the binary analyses, we obtain between 138 and 149 multidimensional dominances, i.e. around three and a half times more than we do in the multi-level analyses.

\footnotetext{
${ }^{16}$ Other aggregation thresholds have been used as well. While the results naturally are sensitive to the threshold choice, the ones shown in Table D1 have been chosen to exemplify the difference between multi-level and binary indicators.

${ }^{17}$ In general we will observe weakly more dominances as the number of outcome combinations decrease.
} 
The corresponding Copeland scores are shown in Table D6. The overall results are similar to those obtained in Table 6, i.e. northern and western European countries most often dominate, and the countries most often dominated are southern and eastern European countries. Though the use of binary indicators enables us to more easily compare European countries and to obtain a more complete ranking, the trade-off is whether the binary indicators adequately describe the distribution of the population in the dimensions considered, or if we are willing to obtain (weakly) fewer dominances by more precisely dividing the population into multidimensional and multi-level outcomes. The results from the spatial and temporal analyses using binary indicators and the associated Copeland scores from the spatial analyses are shown in Tables $\mathrm{D} 2$ through $\mathrm{D} 6$ on the following five pages. 
营|舟

苗の

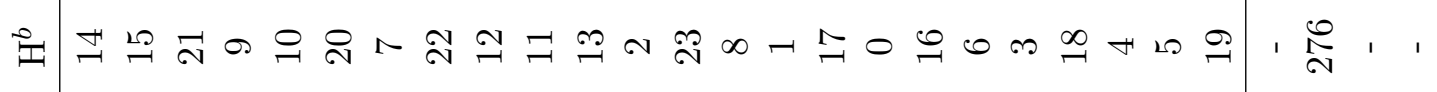

吕 ล

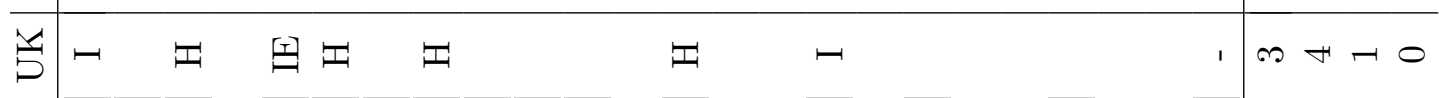

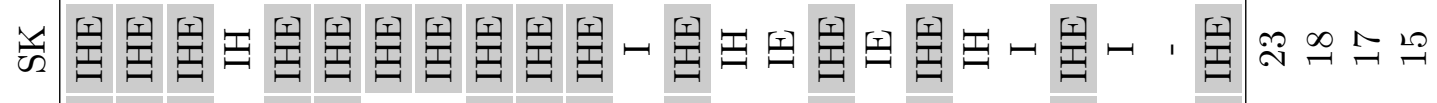

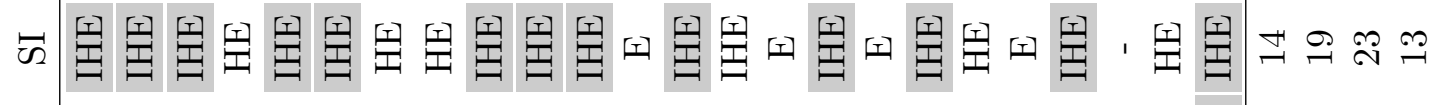

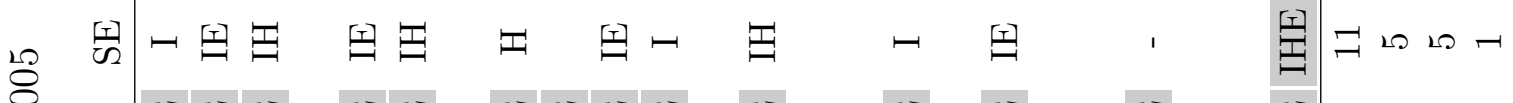

尽

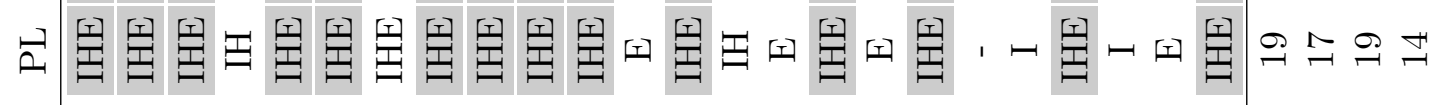

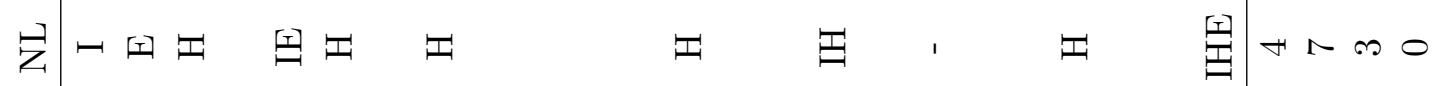

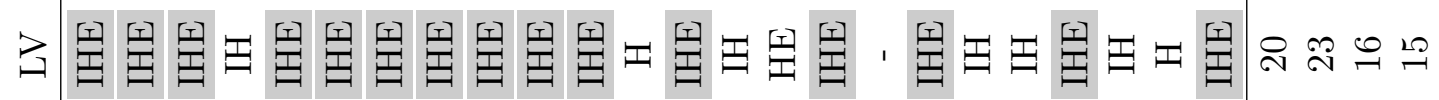

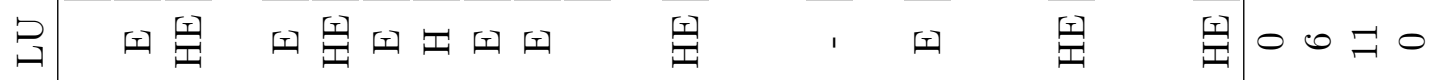

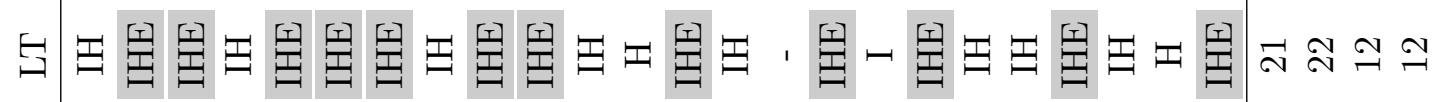

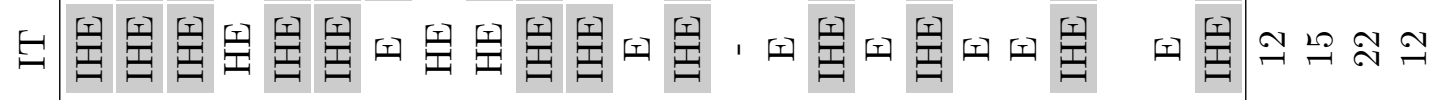

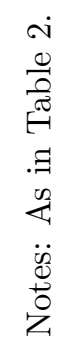

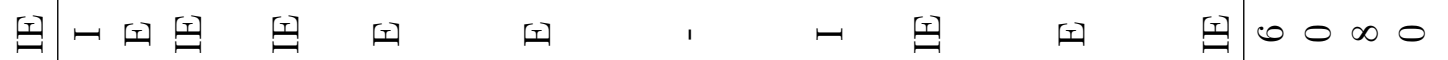

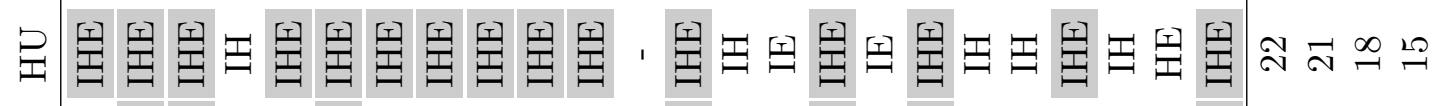

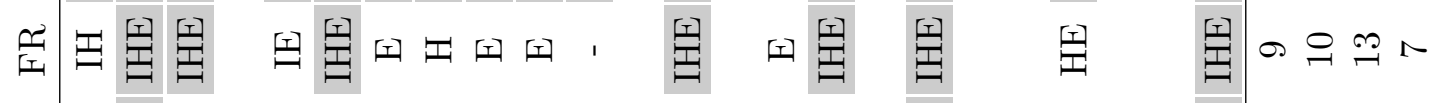

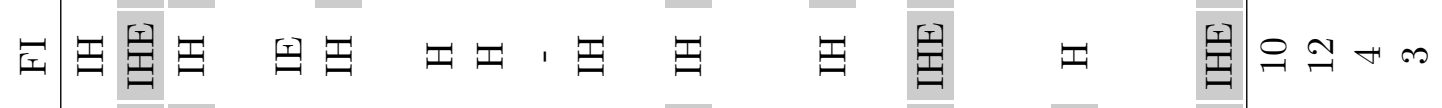

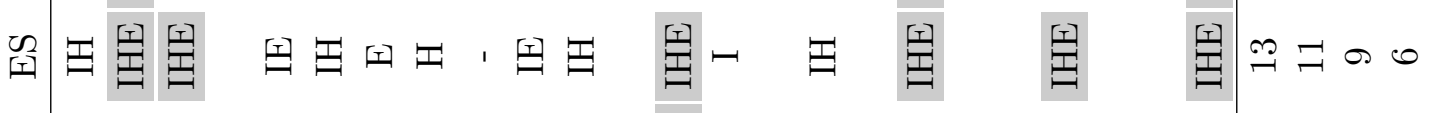

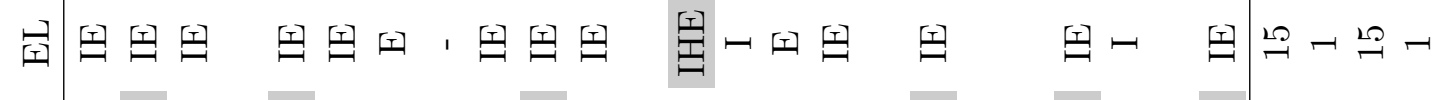

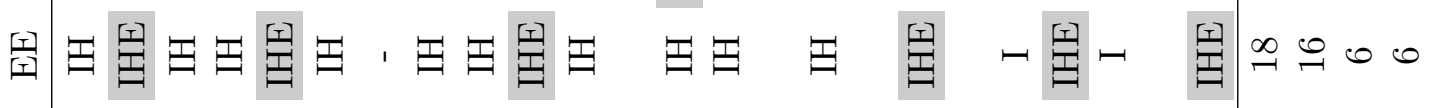

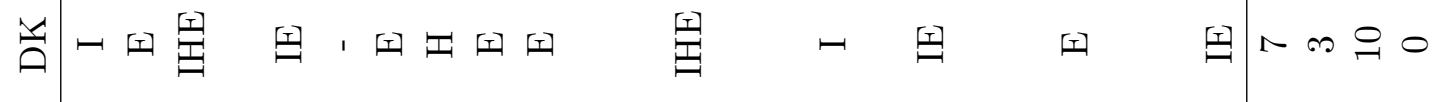

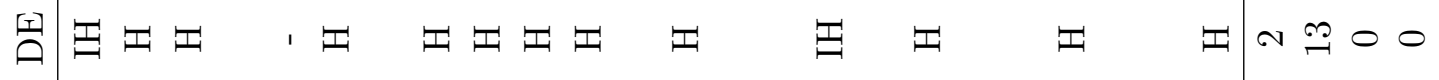

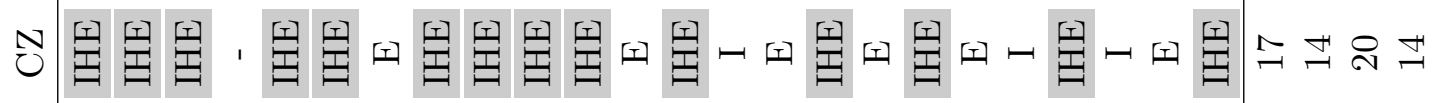

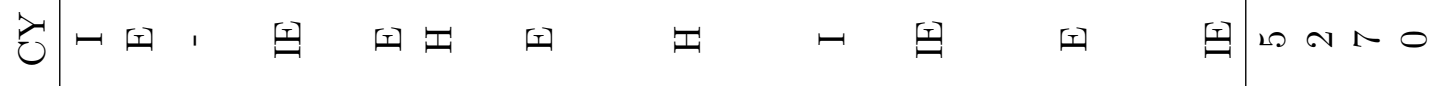

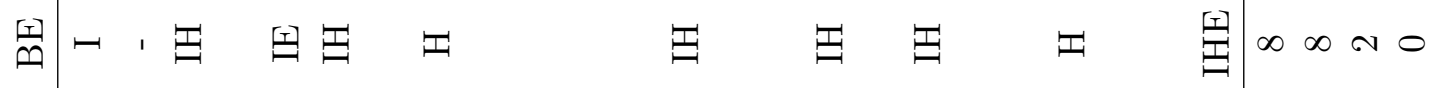

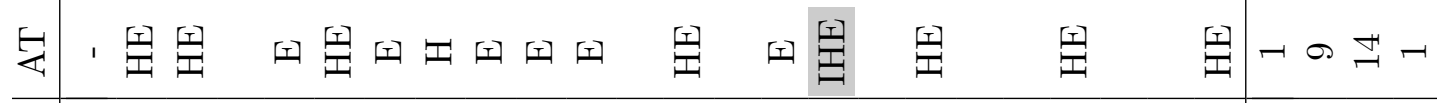

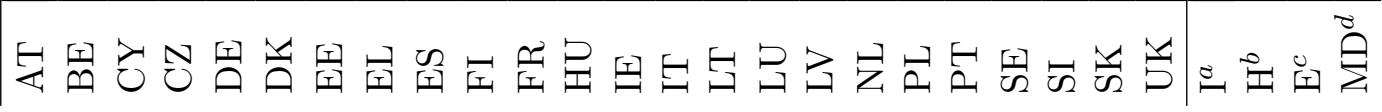


苟的

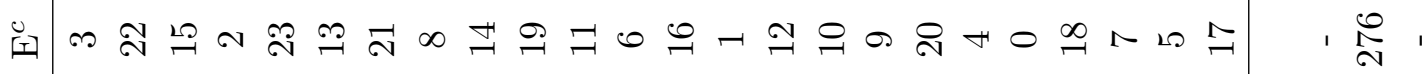

陆

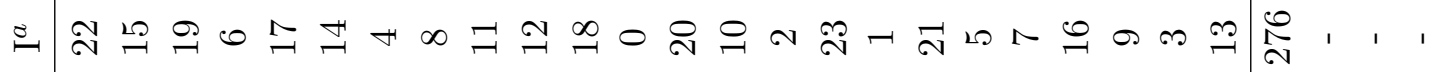

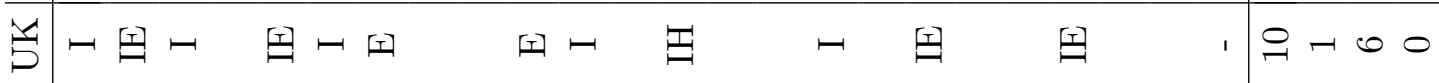

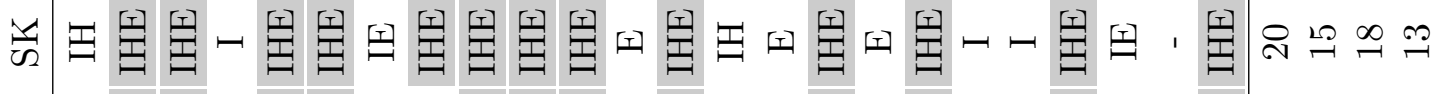

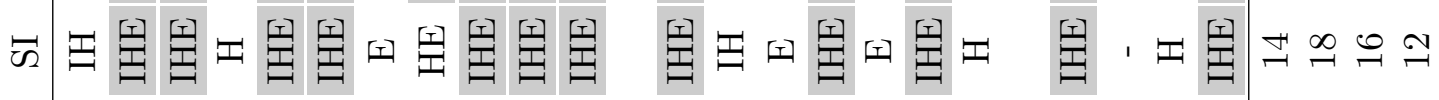

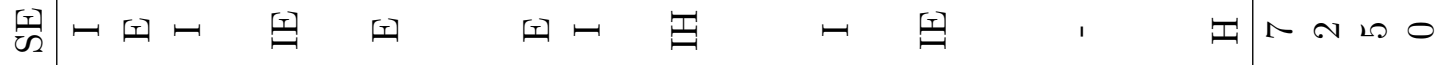

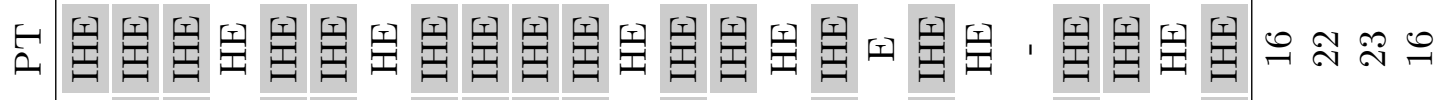

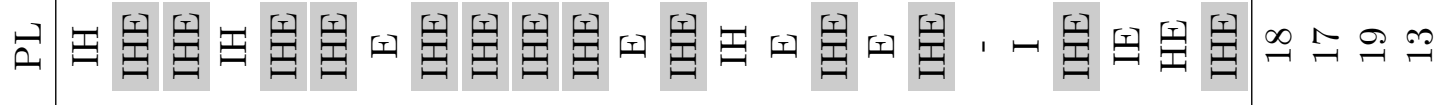

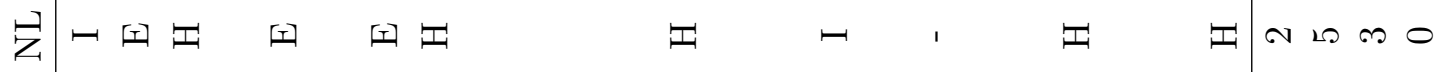

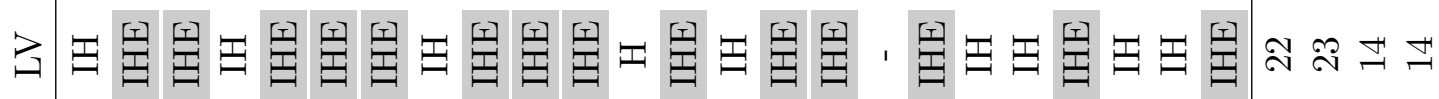

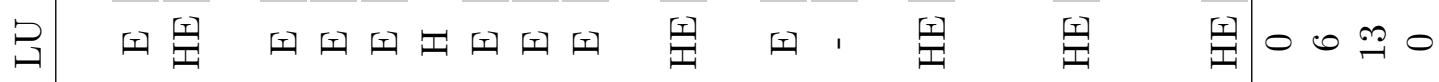

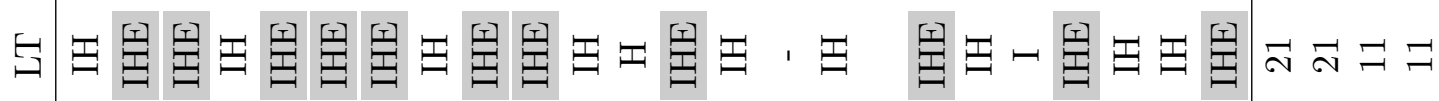

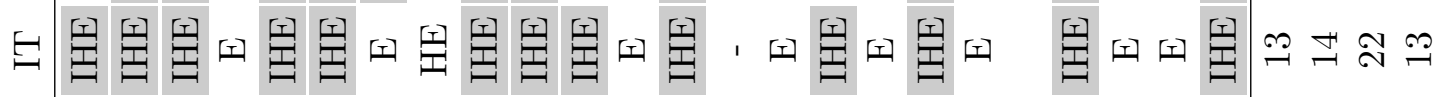

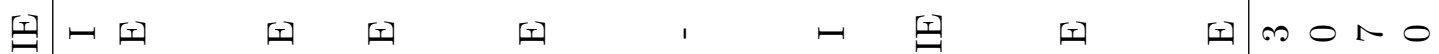

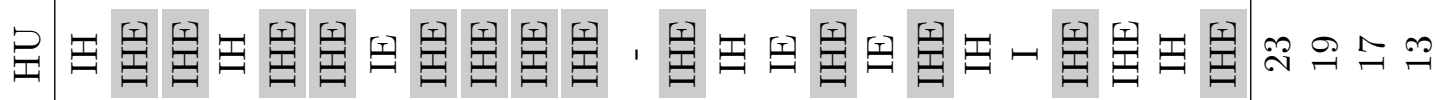

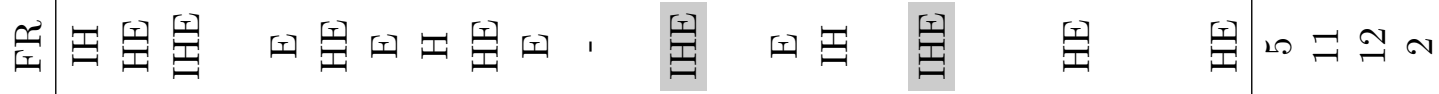

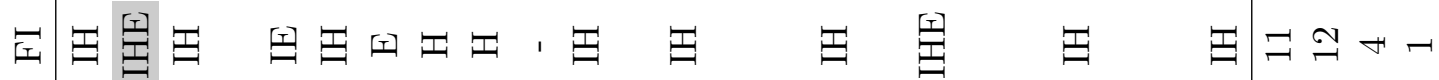

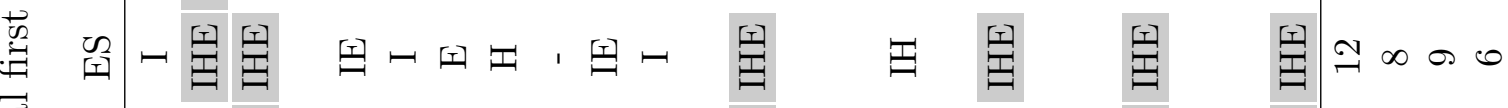

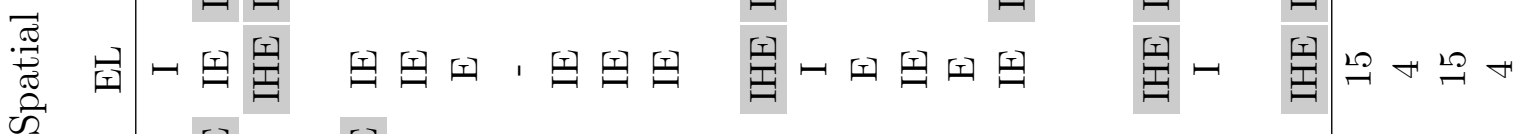

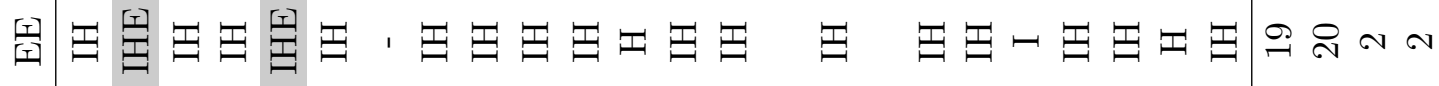

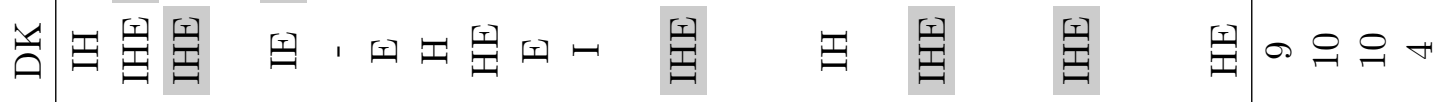

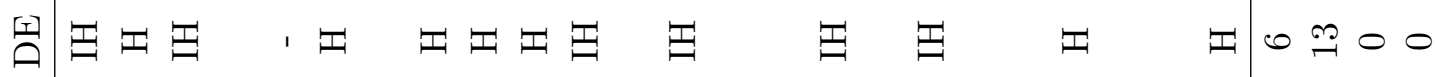

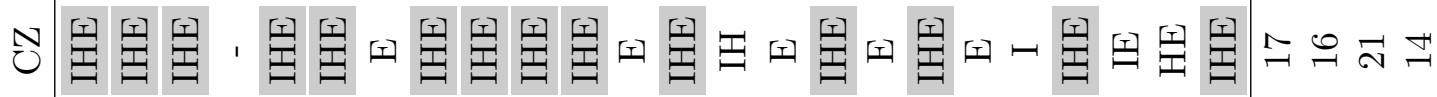

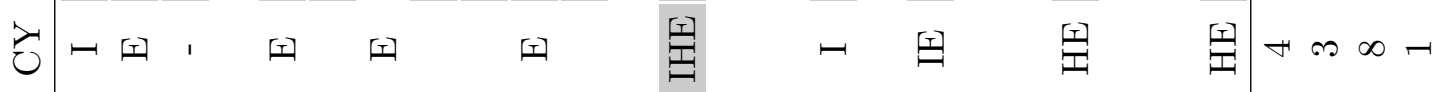

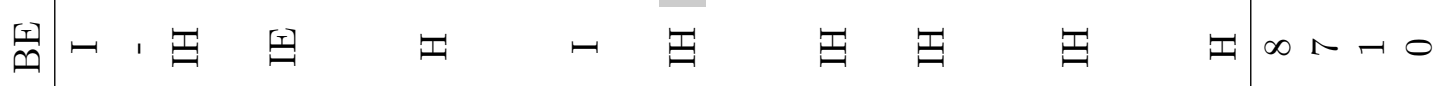

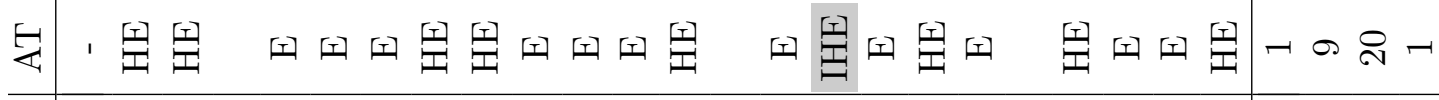

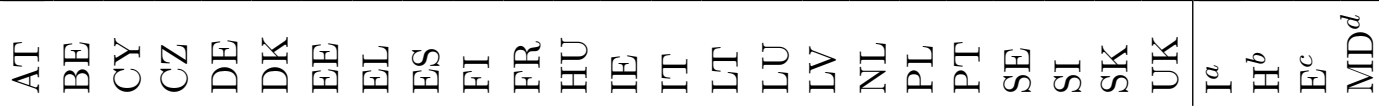




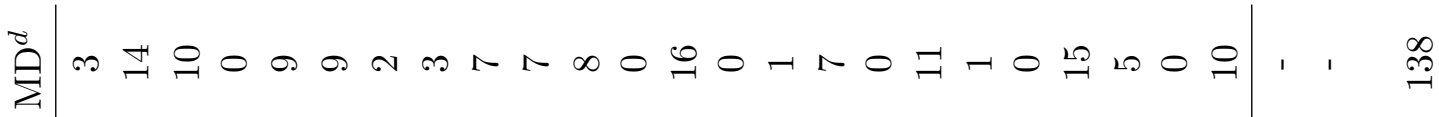

苗の

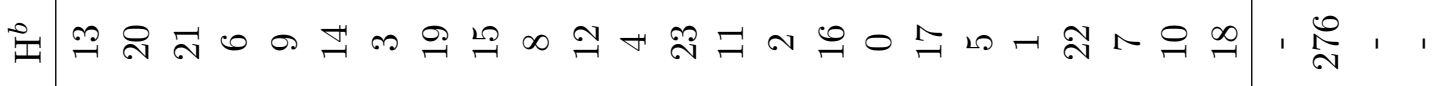

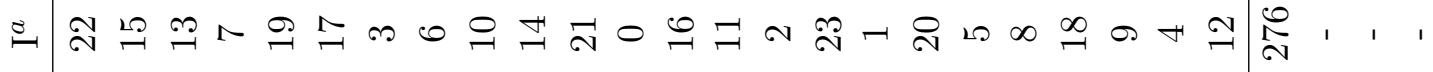

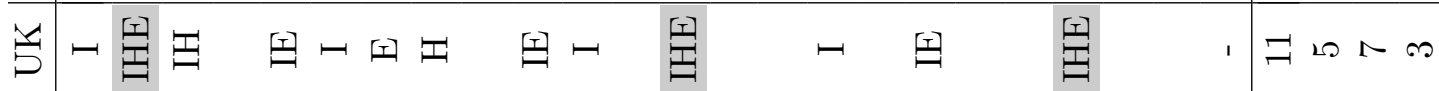

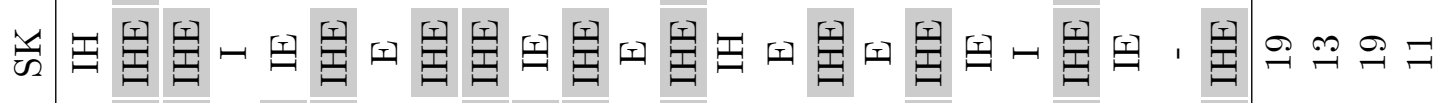

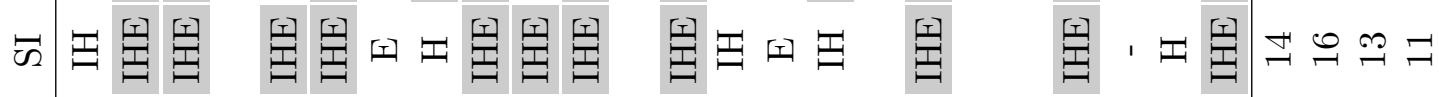

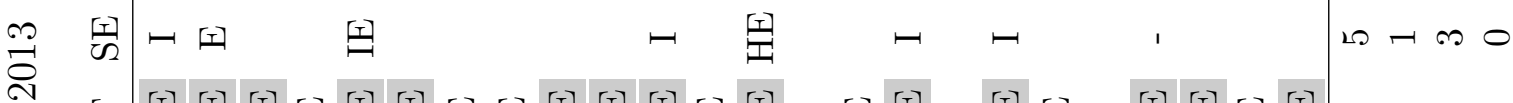

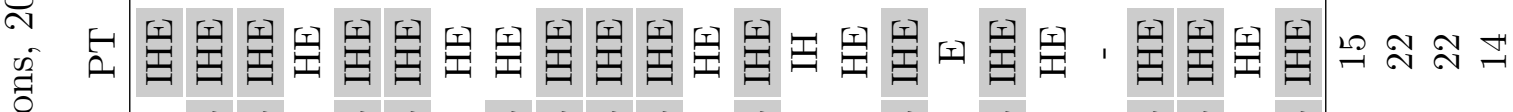

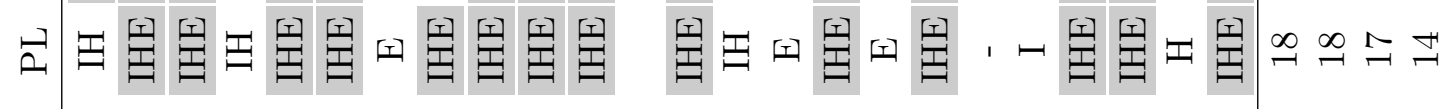

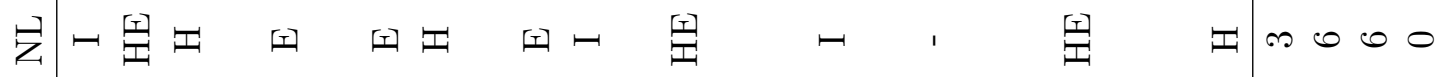

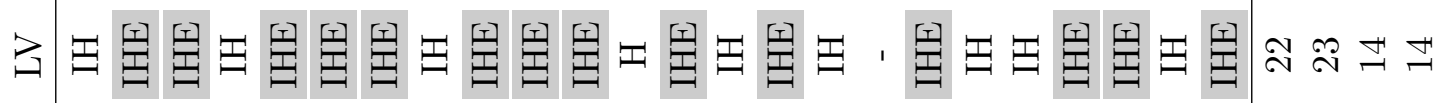

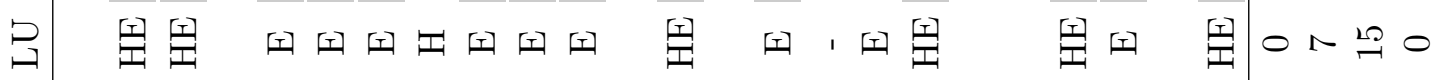

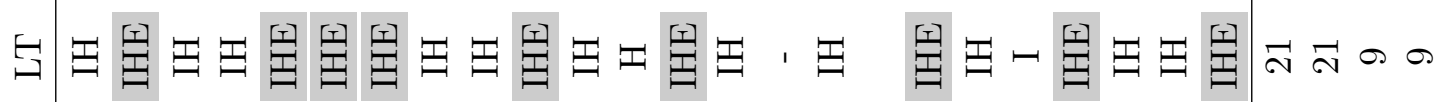

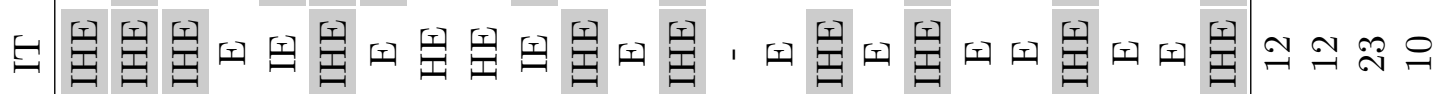
国

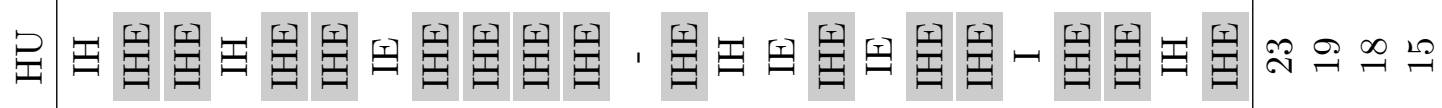

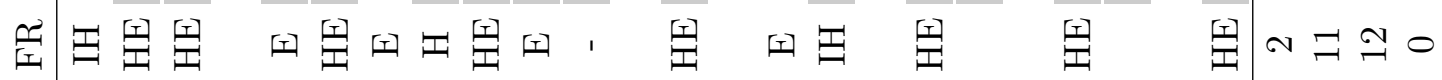

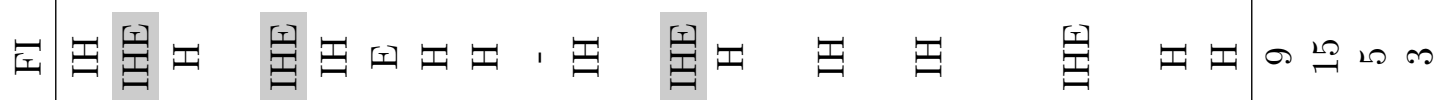

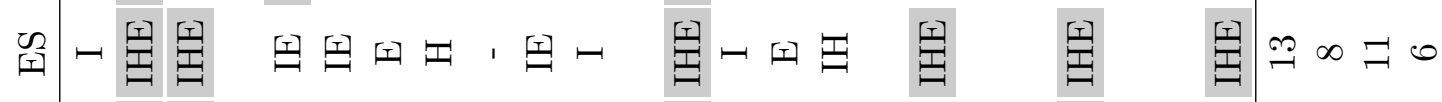

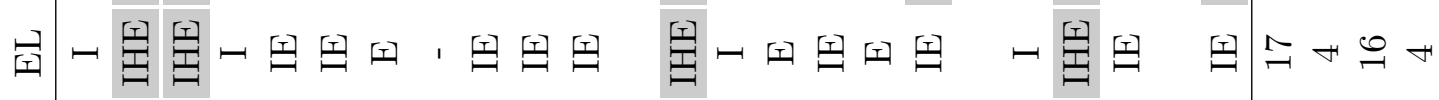

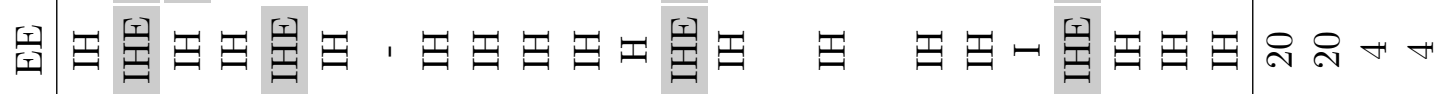

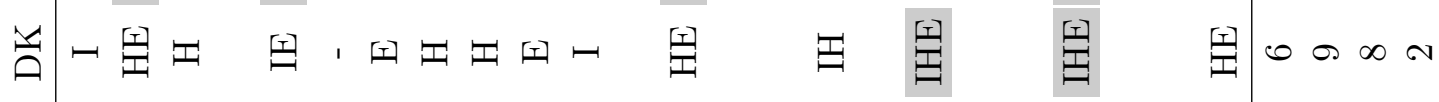

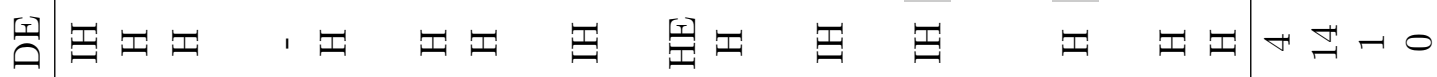

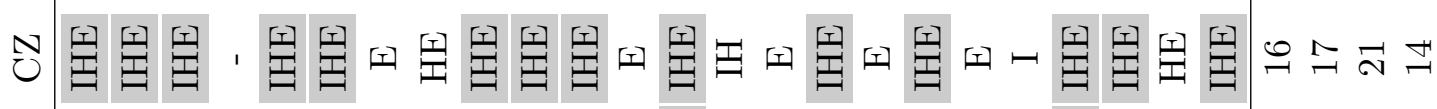

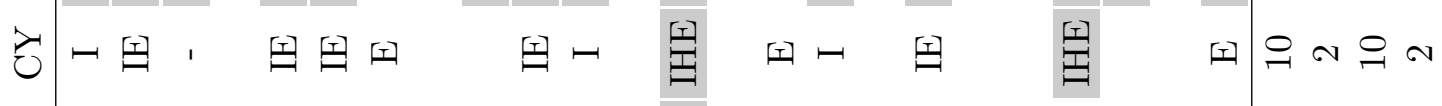

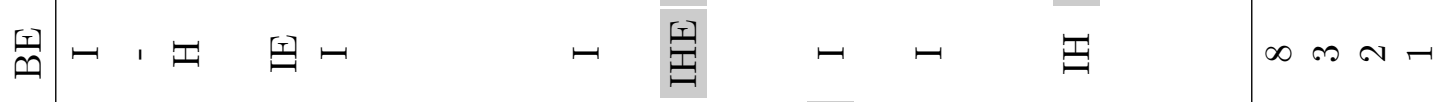

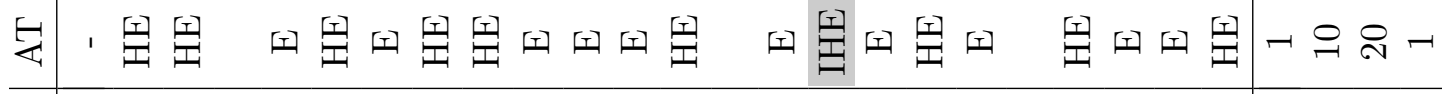

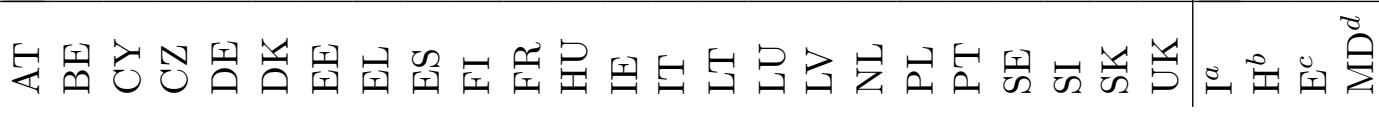


Table D5: Temporal first order dominances, binary indicators of dimensions

Deteriorations over time Improvements over time

\begin{tabular}{lccc|ccc} 
& 05 dom 09 & 05 dom 13 & 09 dom 13 & 09 dom 05 & 13 dom 05 & 13 dom 09 \\
\hline $\mathrm{AT}$ & $\mathrm{IHE}$ & $\mathrm{IH}$ & $\mathrm{IH}$ & & $\mathrm{E}$ & $\mathrm{E}$ \\
$\mathrm{BE}$ & & & & $\mathrm{IHE}$ & $\mathrm{IHE}$ & $\mathrm{IHE}$ \\
$\mathrm{CY}$ & & $\mathrm{I}$ & $\mathrm{I}$ & $\mathrm{IHE}$ & $\mathrm{HE}$ & $\mathrm{HE}$ \\
$\mathrm{CZ}$ & & & $\mathrm{H}$ & $\mathrm{IHE}$ & $\mathrm{IHE}$ & $\mathrm{IE}$ \\
$\mathrm{DE}$ & $\mathrm{I}$ & $\mathrm{I}$ & $\mathrm{IH}$ & $\mathrm{HE}$ & $\mathrm{HE}$ & $\mathrm{E}$ \\
$\mathrm{DK}$ & $\mathrm{H}$ & $\mathrm{H}$ & $\mathrm{H}$ & $\mathrm{IE}$ & $\mathrm{IE}$ & $\mathrm{IE}$ \\
$\mathrm{EE}$ & $\mathrm{H}$ & $\mathrm{H}$ & $\mathrm{I}$ & $\mathrm{IE}$ & $\mathrm{IE}$ & $\mathrm{HE}$ \\
$\mathrm{EL}$ & $\mathrm{H}$ & $\mathrm{IH}$ & $\mathrm{IH}$ & $\mathrm{IE}$ & $\mathrm{E}$ & $\mathrm{E}$ \\
$\mathrm{ES}$ & & & $\mathrm{I}$ & $\mathrm{IHE}$ & $\mathrm{IHE}$ & $\mathrm{HE}$ \\
$\mathrm{FI}$ & $\mathrm{H}$ & $\mathrm{H}$ & $\mathrm{IH}$ & $\mathrm{IE}$ & $\mathrm{IE}$ & $\mathrm{E}$ \\
$\mathrm{FR}$ & $\mathrm{H}$ & $\mathrm{H}$ & $\mathrm{H}$ & $\mathrm{IE}$ & $\mathrm{IE}$ & $\mathrm{IE}$ \\
$\mathrm{HU}$ & & $\mathrm{I}$ & $\mathrm{I}$ & $\mathrm{IHE}$ & $\mathrm{HE}$ & $\mathrm{HE}$ \\
$\mathrm{IE}$ & & $\mathrm{H}$ & $\mathrm{IH}$ & $\mathrm{IHE}$ & $\mathrm{IE}$ & $\mathrm{E}$ \\
$\mathrm{IT}$ & & $\mathrm{I}$ & $\mathrm{I}$ & $\mathrm{IHE}$ & $\mathrm{HE}$ & $\mathrm{HE}$ \\
$\mathrm{LT}$ & & & $\mathrm{IH}$ & $\mathrm{IHE}$ & $\mathrm{IHE}$ & $\mathrm{E}$ \\
$\mathrm{LU}$ & $\mathrm{I}$ & $\mathrm{IH}$ & $\mathrm{IH}$ & $\mathrm{HE}$ & $\mathrm{E}$ & $\mathrm{E}$ \\
$\mathrm{LV}$ & & & $\mathrm{IH}$ & $\mathrm{IHE}$ & $\mathrm{IHE}$ & $\mathrm{E}$ \\
$\mathrm{NL}$ & & $\mathrm{H}$ & $\mathrm{IH}$ & $\mathrm{IHE}$ & $\mathrm{IE}$ & $\mathrm{E}$ \\
$\mathrm{PL}$ & & & $\mathrm{I}$ & $\mathrm{IHE}$ & $\mathrm{IHE}$ & $\mathrm{HE}$ \\
$\mathrm{PT}$ & & & $\mathrm{IH}$ & $\mathrm{IHE}$ & $\mathrm{IHE}$ & $\mathrm{E}$ \\
$\mathrm{SE}$ & & & $\mathrm{I}$ & $\mathrm{IHE}$ & $\mathrm{IHE}$ & $\mathrm{HE}$ \\
$\mathrm{SI}$ & & $\mathrm{I}$ & $\mathrm{I}$ & $\mathrm{IHE}$ & $\mathrm{HE}$ & $\mathrm{HE}$ \\
$\mathrm{SK}$ & & & & $\mathrm{IHE}$ & $\mathrm{IHE}$ & $\mathrm{IHE}$ \\
$\mathrm{UK}$ & $\mathrm{IE}$ & $\mathrm{IH}$ & $\mathrm{IH}$ & $\mathrm{H}$ & $\mathrm{E}$ & $\mathrm{E}$ \\
\hline $\mathrm{I}^{a}$ & 4 & 9 & 19 & 20 & 15 & 5 \\
$\mathrm{H}^{b}$ & 6 & 10 & 14 & 18 & 14 & 10 \\
$\mathrm{E}^{c}$ & 2 & 0 & 0 & 22 & 24 & 24 \\
$\mathrm{MD}$ & 1 & 0 & 0 & 15 & 9 & 2 \\
& & & & & &
\end{tabular}

Notes: As in Table 5 . 
Table D6: Copeland scores and corresponding ranking of EU member states, binary indicators of dimensions

\begin{tabular}{ccccccccc}
\multicolumn{7}{c}{2005} & \multicolumn{7}{c}{2009} \\
\hline Rank & Country & Score & Rank & Country & Score & Rank & Country & Score \\
\hline 1 & UK & 0.609 & 1 & IE & 0.609 & 1 & IE & 0.696 \\
2 & BE & 0.565 & 2 & BE & 0.522 & 2 & SE & 0.652 \\
2 & NL & 0.565 & 2 & NL & 0.522 & 3 & BE & 0.565 \\
4 & IE & 0.522 & 2 & SE & 0.522 & 4 & NL & 0.478 \\
5 & CY & 0.478 & 5 & CY & 0.478 & 5 & DE & 0.391 \\
5 & LU & 0.478 & 5 & UK & 0.478 & 6 & CY & 0.348 \\
7 & DE & 0.435 & 7 & DE & 0.435 & 6 & FR & 0.348 \\
7 & DK & 0.435 & 8 & LU & 0.391 & 8 & DK & 0.304 \\
7 & SE & 0.435 & 9 & FI & 0.348 & 8 & LU & 0.304 \\
10 & AT & 0.304 & 10 & FR & 0.261 & 8 & UK & 0.304 \\
10 & FI & 0.304 & 11 & DK & 0.217 & 11 & FI & 0.174 \\
12 & EL & 0.217 & 12 & ES & 0.130 & 12 & AT & 0.087 \\
13 & ES & 0.087 & 13 & AT & 0.087 & 13 & ES & 0.043 \\
14 & FR & 0.043 & 14 & EL & 0.043 & 14 & EL & -0.043 \\
15 & EE & -0.087 & 15 & EE & 0 & 15 & EE & -0.087 \\
16 & IT & -0.522 & 16 & LT & -0.435 & 16 & SI & -0.261 \\
16 & LT & -0.522 & 17 & SI & -0.478 & 17 & LT & -0.348 \\
18 & SI & -0.565 & 18 & IT & -0.522 & 18 & IT & -0.435 \\
19 & CZ & -0.609 & 19 & HU & -0.565 & 19 & SK & -0.478 \\
19 & PL & -0.609 & 19 & PL & -0.565 & 20 & PL & -0.565 \\
19 & PT & -0.609 & 19 & SK & -0.565 & 21 & CZ & -0.609 \\
22 & HU & -0.652 & 22 & CZ & -0.609 & 21 & LV & -0.609 \\
22 & LV & -0.652 & 22 & LV & -0.609 & 21 & PT & -0.609 \\
22 & SK & -0.652 & 24 & PT & -0.696 & 24 & HU & -0.652
\end{tabular}

Notes: As in Table 6 . 